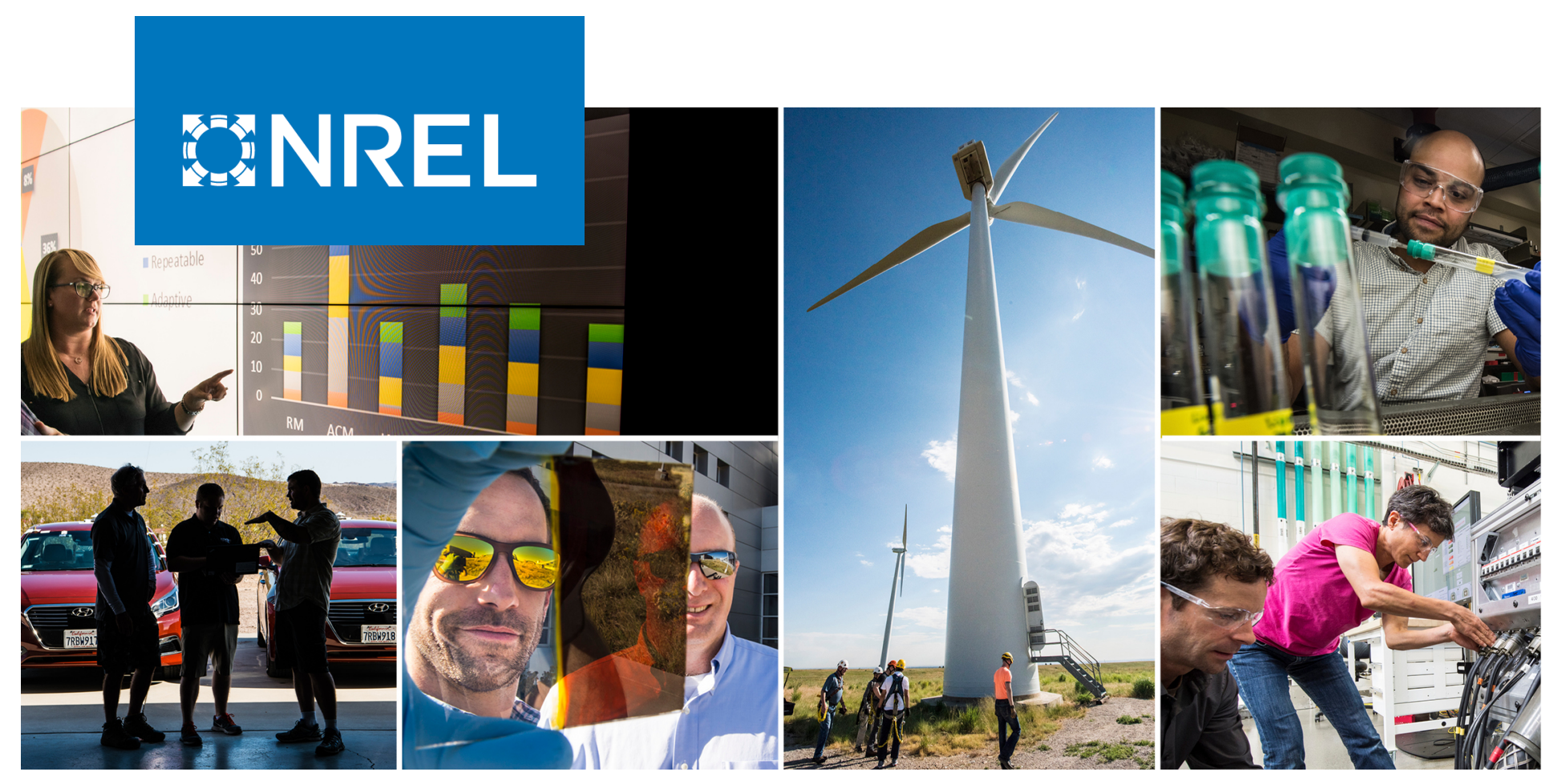

\title{
Competitiveness Metrics for Electricity System Technologies
}

Trieu Mai, ${ }^{1}$ Matthew Mowers, ${ }^{2}$ and Kelly Eurek ${ }^{1}$

${ }^{1}$ National Renewable Energy Laboratory

2 Independent Contractor

NREL is a national laboratory of the U.S. Department of Energy Office of Energy Efficiency \& Renewable Energy

Operated by the Alliance for Sustainable Energy, LLC

This report is available at no cost from the National Renewable Energy Laboratory (NREL) at www.nrel.gov/publications.
Technical Report

NREL/TP-6A20-72549

February 2021 


\title{
GHREL
}

\section{Competitiveness Metrics for Electricity System Technologies}

\author{
Trieu Mai, ${ }^{1}$ Matthew Mowers, ${ }^{2}$ and Kelly Eurek ${ }^{1}$
}

${ }^{1}$ National Renewable Energy Laboratory

${ }^{2}$ Independent Contractor

\section{Suggested Citation}

Mai, Trieu, Matthew Mowers, and Kelly Eurek. 2021. Competitiveness Metrics for Electricity System Technologies. Golden, CO: National Renewable Energy Laboratory. NREL/TP-6A20-72549. https://www.nrel.gov/docs/fy21osti/72549.pdf.

NREL is a national laboratory of the U.S. Department of Energy Office of Energy Efficiency \& Renewable Energy Operated by the Alliance for Sustainable Energy, LLC

This report is available at no cost from the National Renewable Energy Laboratory (NREL) at www.nrel.gov/publications.

Contract No. DE-AC36-08GO28308
Technical Report NREL/TP-6A20-72549 February 2021

National Renewable Energy Laboratory 15013 Denver West Parkway Golden, CO 80401 303-275-3000 • www.nrel.gov 


\section{NOTICE}

This work was authored in part by the National Renewable Energy Laboratory, operated by Alliance for Sustainable Energy, LLC, for the U.S. Department of Energy (DOE) under Contract No. DE-AC36-08GO28308. Funding provided by U.S. Department of Energy Office of Energy Efficiency and Renewable Energy Wind Energy Technologies Office. The views expressed herein do not necessarily represent the views of the DOE or the U.S. Government.

This report is available at no cost from the National Renewable Energy Laboratory (NREL) at www.nrel.gov/publications.

U.S. Department of Energy (DOE) reports produced after 1991 and a growing number of pre-1991 documents are available free via www.OSTI.gov.

Cover Photos by Dennis Schroeder: (clockwise, left to right) NREL 51934, NREL 45897, NREL 42160, NREL 45891, NREL 48097, NREL 46526.

NREL prints on paper that contains recycled content. 


\section{Preface}

The economic competitiveness of power generation technologies is a topic of much interest to a diverse set of electric utility participants. Levelized cost of electricity (LCOE) is commonly used as a metric to compare technologies and guide research and development goals. LCOE facilitates a comparison between technologies with varying degrees of capital- and fuel-intensiveness and is relatively simple to calculate. However, the application of LCOE to compare the competitiveness of technologies has several well-known shortcomings, particularly because LCOE is not designed to capture a technology's full economic value to the system. Despite the common recognition of these shortcomings, no consensus exists on an alternative metric that can overcome these shortcomings, be readily quantified, and be understandable by a broad range of stakeholders.

The analysis presented in this report explores competitiveness metrics in the context of electricity system technologies (inclusive of generation, transmission, storage, and other electricity system assets), and the economic value and cost concepts that inform the metrics. This work is intended to serve multiple objectives. The first objective is to provide a conceptual understanding of the components needed when considering the economic competitiveness of electricity system technologies. A second purpose is to summarize and categorize existing metrics from the literature that have been introduced in part to convey the economic competitiveness of electricity system technologies. In addition, this report presents a new set of competitiveness metrics and compares them with existing ones. A third objective of the analysis presented is to demonstrate how the competitiveness metrics, and their components, can be quantitatively estimated using an electricity system model.

The quantifications demonstrated in this report are intended to illustrate an application of the underlying concepts related to the economic valuation of electricity system technologies and to provide a basis for comparing various competitiveness metrics. None of the numerical values presented in this report is intended to be a definitive estimate of the economic value of the technologies modeled. Such economic value estimates are highly dependent on the system scenarios considered, assumptions related to market conditions, assumptions related to the cost, performance, technical capabilities of the individual technologies, and the ability of the model used to reasonably reflect system requirements and the grid services provided by the technology to meet those requirements. Significant uncertainties and limitations of the quantifications are noted throughout the report. Additional research is needed to more robustly assess the relative competitiveness of different technologies, including research into and application of higherfidelity modeling designed to comprehensively reflect all sources of technology cost and value under a wide range of future scenarios.

In summary, this report is primarily conceptual in nature-with examples of modeling used only to illustrate the concepts - and it is designed to serve as a reference for future quantitative analyses of the competitiveness of electricity system technologies. 


\section{Acknowledgments}

We thank the following individuals for their comments and reviews of a draft version of this report: Audun Botterud and Todd Levin (Argonne National Laboratory); Marija Prica (Case Western University); Juliet Simpson and Eric Loth (University of Virginia, Department of Mechanical and Aerospace Engineering); David Daniels, Cara Marcy, Chris Namovicz, and Manussawee Sukunta (U.S. Energy Information Administration); Charlie Gay, Patrick Gilman, Kevin Lynn, Ookie Ma, Alejandro Moreno, Paul Donohoo-Vallett, and Stephen Walls (U.S. Department of Energy); Bryan Mignone (ExxonMobil Research and Engineering Company); Brent Dixon, Jason Hansen, and Christian Rabiti (Idaho National Laboratory); Simon Müller and Brent Wanner (International Energy Agency); Andrew Mills and Ryan Wiser (Lawrence Berkeley National Laboratory); Dan Bilello, Wesley Cole, Paul Denholm, Pieter Gagnon, Eric Lantz, Mark O’Malley, Gian Porro, Daniel Steinberg, Yinong Sun, and Rich Tusing (NREL); and Geoff Rothwell (Stanford University, retired). We also thank Alexandra Newman (Colorado School of Mines) for useful discussions related to optimization modeling. Editing support was provided by Mary Lukkonen and Mike Meshek (NREL). All errors or omissions are the sole responsibility of the authors.

We gratefully acknowledge funding for this work from the U.S. Department of Energy's Office of Energy Efficiency and Renewable Energy under contract number DE-AC36-08GO28308. We especially thank Patrick Gilman from the Wind Energy Technologies Office for his support. 


\section{List of Acronyms and Abbreviations}

$\begin{array}{ll}\text { AC } & \text { alternating current } \\ \text { A/S } & \text { ancillary service(s) } \\ \text { BA } & \text { balancing area } \\ \text { BCR } & \text { benefit-cost ratio } \\ \text { CEM } & \text { capacity expansion model } \\ \text { FOM } & \text { fixed operations and maintenance } \\ \text { IRR } & \text { internal rate of return } \\ \text { ISO } & \text { independent system operator } \\ \text { LACE } & \text { levelized avoided cost of energy } \\ \text { LCOE } & \text { levelized cost of electricity } \\ \text { LMP } & \text { locational marginal price } \\ \text { LVOE } & \text { levelized value of electricity } \\ \text { LP } & \text { linear program } \\ \text { MILP } & \text { mixed integer linear program } \\ \text { NERC } & \text { North American Electric Reliability Corporation } \\ \text { NG-CC } & \text { natural gas combined cycle } \\ \text { NG-CCS } & \text { natural gas with carbon capture and sequestration } \\ \text { NG-CT } & \text { natural gas combustion turbine } \\ \text { NPV } & \text { net present value } \\ \text { NREL } & \text { National Renewable Energy Laboratory } \\ \text { NVOC } & \text { net value of capacity } \\ \text { NVOE } & \text { net value of electricity } \\ \text { O\&M } & \text { operations and maintenance } \\ \text { PV } & \text { photovoltaic } \\ \text { R\&D } & \text { research and development } \\ \text { ReEDS } & \text { Regional Energy Deployment System } \\ \text { ROI } & \text { return on investment } \\ \text { RTO } & \text { regional transmission operator } \\ \text { VOM } & \text { variable operations and maintenance } \\ \text { VRE } & \end{array}$




\section{Executive Summary}

\section{Motivation: Simple Technology Metrics to Capture Complex Interactions}

The economic competitiveness of power generation technologies is a topic of much interest to diverse electric industry participants, where competitiveness is an indication of whether a technology is economically viable, how far a technology is from viability, and the relative viability between options (i.e., their rank order). From the perspective of a central electricity system planner - which is the perspective we take throughout this report unless otherwise noted - competitiveness is defined based on the impact on total system costs. Although evaluating competitiveness is of keen interest, not all interested parties have access to the extensive engineering and economic tools needed to comprehensively assess competitiveness. So, simplified metrics can help in communications about the competitiveness of electric system technologies.

A common metric used to track technology progress over time and to compare electric generation technologies is the levelized cost of electricity (LCOE). LCOE is the cost that, if assigned to every unit of electricity produced by an asset over an evaluation period, will equal the total cost of that asset over the period when discounted to a base year. It is well established that LCOE is an incomplete metric because although it reflects total costs and the amount of electrical energy produced, LCOE does not consider the monetary value of that energy to the system, which varies by location and time, and LCOE ignores the value of other services altogether. In short, LCOE is not designed to capture a technology's full economic value to the system, which we refer to as its system value.

An asset's total system value is derived from the suite of services (e.g., energy, capacity, and ancillary services) that it provides. From the perspective of a central electricity system planner, the value attributed to a technology for each grid service is the product of the marginal cost of that service and the amount of service provided by the asset. ${ }^{1}$ When in long-run equilibrium, this approach will result in marginal costs that recover both the fixed and operating costs of all generators. Total system value is simply the sum of the values over all services that the technology provides. From this definition and in the context of a new investment decision, system value reflects the potential marginal economic value from displacing or avoiding the cost of providing the services from other (marginal) assets. On the other hand, total cost for a new investment is the aggregate of expenditures (e.g., capital, fuel, and operations and maintenance) needed to build and operate the asset to deliver the grid services. Defining system value and costs in this manner enables a direct reflection of an asset's impact on total system costs. These principles are also intrinsic in optimization modeling - commonly used by electric utility planners, system operators, and other electric industry stakeholders - which provides a practical means to quantify technology cost and system value as we demonstrate in this report.

Despite the straightforward manner in which system value is conceptually defined, system value of electricity technologies - including generation, transmission, and end-use options — can be challenging to comprehensively and accurately quantify due to (1) the numerous and diverse grid services needed to operate a reliable power system; (2) variation in the economic value of the grid

\footnotetext{
${ }^{1}$ These metrics can also be used for other perspectives (e.g., market value vs. system value); however, this report takes the central system planner perspective only.
} 
services by location, time, and system state; and (3) the unique characteristics of different electric system assets that influence their ability and cost for providing services. While difficult to assess due to these complexities, estimating system value is critical for determining competitiveness. An ideal metric would combine system value with technology costs in a manner that accurately conveys competitiveness-where a technology's competitiveness, from a system planner perspective, is the degree to which overall system costs are impacted by an asset.

\section{Key Takeaways}

- The economic competitiveness of an electricity system technology-as reflected by metrics designed to convey competitiveness-are determined from both the cost of the technology and its value to the system, where system value is derived from the grid services the technology provides.

- System value is manifested through the interactions between the technology and the interconnected power system; accordingly, system value is sensitive to the conditions of the system, which vary based on short- and long-term changes in the system.

- From a central system planning perspective, a technology's total system value is the product of the marginal cost to provide a service and the amount of grid services provided by the asset, summed over all services the technology provides.

- How components of cost and value are combined in a competitiveness metric can affect the robustness of the metric. Existing metrics that are based on the difference between cost and system value normalized by a physical unit (for example MWh or kW) can distort the suggested competitiveness.

- System profitability metrics, which are introduced in this report, can enable effective economic comparisons of all types of electricity system technologies by placing all services on an equivalent monetary basis.

- Capacity expansion modeling can be used to calculate competitiveness metrics. The metrics are generated from, and cannot replace, the modeling.

- Quantification of the metrics, and the metrics themselves, involves certain key limitations and caveats.

\section{A Review of Existing Metrics and an Introduction of Profitability-Based Metrics}

While individual components of costs and system value can shed light on aspects of technology competitiveness, a competitiveness metric combines these components into a single measure to convey overall economic competitiveness. We review several metrics (Table ES-1, next page) that can be categorized into three groups based on whether they are comprehensive (i.e., account for both costs and system value) and whether they have been previously introduced in the literature. We only compare normalized metrics, which are relevant for comparisons between classes of technologies rather than individual projects. Appendix A provides more-rigorous definitions and mathematical expressions for the metrics shown in Table ES-1. 
Table ES-1. Competitiveness Metrics Reviewed

\begin{tabular}{|c|c|c|c|}
\hline & Metric & $\begin{array}{l}\text { Conceptual Expression } \\
\text { [typical units] }\end{array}$ & Definition \\
\hline \multirow{2}{*}{ 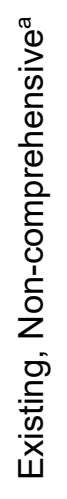 } & $\begin{array}{l}\text { Levelized } \\
\text { Cost of } \\
\text { Electricity } \\
\text { (LCOE) }\end{array}$ & $\begin{array}{l}\text { Cost/Energy } \\
\text { [\$/MWh] }\end{array}$ & $\begin{array}{l}\text { LCOE is the cost that, if assigned to every unit of } \\
\text { electricity by an asset over an evaluation period, } \\
\text { will equal the total costs during that same period } \\
\text { when discounted to the base year. }\end{array}$ \\
\hline & $\begin{array}{l}\text { Levelized } \\
\text { Value of } \\
\text { Electricity } \\
\text { (LVOE) }\end{array}$ & $\begin{array}{l}\text { Value/Energy } \\
\text { [\$/MWh] }\end{array}$ & $\begin{array}{l}\text { LVOE is the value that, if assigned to every unit } \\
\text { of electricity generated by an asset over an } \\
\text { evaluation period, will equal its total system value } \\
\text { during that same period when discounted to the } \\
\text { base year. }\end{array}$ \\
\hline \multirow{3}{*}{ 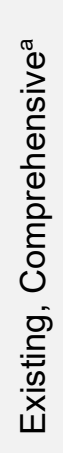 } & $\begin{array}{l}\text { Net Value of } \\
\text { Electricity } \\
\text { (NVOE) }\end{array}$ & $\begin{array}{l}\text { (Value - Cost)/Energy } \\
\text { [\$/MWh] }\end{array}$ & $\begin{array}{l}\text { NVOE is the difference between LVOE } \\
\text { and LCOE. }\end{array}$ \\
\hline & $\begin{array}{l}\text { Net Value of } \\
\text { Capacity } \\
\text { (NVOC) }\end{array}$ & $\begin{array}{l}\text { (Value - Cost)/Capacity } \\
{[\$ / \mathrm{kW}-\mathrm{yr}]}\end{array}$ & $\begin{array}{l}\text { NVOC is the difference in an asset's annual } \\
\text { system value and its annualized costs, divided by } \\
\text { the installed capacity of the asset. }\end{array}$ \\
\hline & $\begin{array}{l}\text { System } \\
\text { LCOE }\end{array}$ & $\begin{array}{l}\text { (Cost - Value)/Energy + } \\
\text { Benchmark Price } \\
{[\$ / \mathrm{MWh}]}\end{array}$ & $\begin{array}{l}\text { System LCOE is the negative of NVOE but } \\
\text { further adjusted by a benchmark price. }\end{array}$ \\
\hline 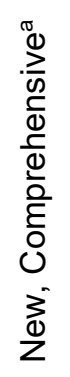 & $\begin{array}{l}\text { System } \\
\text { Profitability }\end{array}$ & $\begin{array}{l}\mathrm{f}(\text { Value/Cost }) \\
\text { [unitless] }\end{array}$ & $\begin{array}{l}\text { System profitability metrics are functions of the } \\
\text { ratio between total system value and cost. } \\
\text { Examples include system benefit-cost ratio } \\
\text { (value/cost), system return on investment } \\
\text { (value/cost - 1), and system profit margin (1 - } \\
\text { cost/value). }\end{array}$ \\
\hline
\end{tabular}

${ }^{a}$ The metrics are grouped according to whether they are existing or new metrics and whether they can comprehensively consider both costs and system value.

${ }^{\mathrm{b}}$ The benchmark price can be arbitrarily chosen, although it should be consistent across technologies for a meaningful comparison. Benchmark prices can vary by scenario and year. Various benchmark prices have been suggested in the literature, including the annual average of hourly marginal electricity prices or an average price in a no-renewables system.

The first group of metrics in Table ES-1 includes LCOE and the levelized value of electricity (LVOE), ${ }^{2}$ both of which are known metrics but neither of which comprehensively includes both costs and value. LCOE omits a technology's system value and LVOE omits the costs to build and operate the technology.

\footnotetext{
${ }^{2}$ LVOE has the same form as LCOE except costs are replaced by system value; in other words, an asset's LVOE is the present value of its total economic system value divided by the present value of electrical energy produced by the asset. Many similar measures to LVOE have been used in the literature, but there is no consensus on the term used.
} 
The second group (in the shaded rows of the table) includes known metrics only, but each metric from this group comprehensively includes costs and system value by taking their difference. In fact, many of these metrics were introduced to overcome the shortcomings of LCOE by incorporating system value. Metrics in the second group include the net value of electricity (NVOE), net value of capacity (NVOC), and system LCOE. All the metrics in this group levelize or normalize the monetary net value or net cost by a physical quantity such as energy or installed capacity. NVOE is simply the difference between LVOE and LCOE. NVOC is the annualized net value per unit of installed capacity. ${ }^{3}$ System LCOE is closely related to NVOE as it can be expressed as a benchmark price minus NVOE, where, in principle, the benchmark price can be arbitrarily chosen. However, because one of the primary motivations of system LCOE is to quantify renewable "integration costs," benchmark prices have been chosen to reveal the characteristics of variable renewable technologies. ${ }^{4}$ By considering both cost and system value, metrics from the second group can answer the binary question of whether a technology option is economically viable. For example, an option with a positive net value (either NVOE or NVOC) would be economically viable, as that would mean its total system value exceeds its total costs.

Although the existing metrics from the second group - NVOE, NVOC, and system LCOE-do indeed offer improvements to LCOE in that they also consider system value, they do not always robustly convey relative technology competitiveness or how far a potential investment might be from profitability. To this end, we introduce a new set of competitiveness metrics in the third group from Table ES-1, which we refer to as "system profitability metrics." Like the metrics from the second group, the system profitability metrics comprehensively consider both cost and system value; however, the new metrics combine cost and value differently than the "net value" metrics from the second group.

System profitability metrics can take many forms, but their key defining trait is that they are all a function of the ratio of total system value to total costs. In other words, instead of normalizing with a physical quantity, the system profitability metrics normalize by total costs. The simplest conceptual form is the ratio itself, which we refer to as the system benefit-cost ratio (BCR). An asset with a system BCR of one or more would be economically viable. By using the dimensionless ratio of total system value to total cost, the system profitability metrics directly reflect how much incremental value would be gained for every dollar expended for a new investment. The system profitability metrics allow for effective economic comparisons of all types of technologies, regardless of the mixes of services that are provided, by putting all services on an equivalent (monetary) basis. In addition to system BCR, other functional forms of the system profitability metrics include system return-on-investment (ROI) and system profit margin. ${ }^{5}$ System BCR, system ROI, and system profit margin are all dimensionless.

\section{Assessing Advantages and Disadvantages of the Metrics}

The competitiveness metrics presented above have various strengths and weaknesses that should be recognized for their appropriate choice and/or interpretation. The incompleteness of LCOE

\footnotetext{
${ }^{3}$ As with LVOE, the literature includes various terms for measures that are functionally identical or similar to NVOE and NVOC.

${ }^{4}$ For example, the LVOE of a "flat-block" generator or the average electricity price have been chosen as a benchmark price in the literature.

${ }^{5}$ System ROI $=$ value/cost -1 . System profit margin $=1-$ cost/value.
} 
has already been raised, but one advantage of LCOE is that it can be more straightforward to calculate than the other metrics. All the other metrics are also sensitive to the system, including its generation mix, network topology, system flexibility, and desired attributes (e.g., desired level of reliability). However, as discussed previously, only the comprehensive metrics from the second and third groups in Table ES-1 can indicate the economic viability of a technology. For example, an asset with positive NVOE, NVOC, and system ROI is viable (i.e., its system value equals or exceeds its costs). System $\mathrm{LCOE}^{6}$ can also separate technologies that are economically viable from those that are not, but the distinction requires knowledge of the benchmark price used in the metric. This additional step can create confusion, especially because the benchmark price can vary across scenarios and over time within a scenario, and it can be defined differently by different studies.

In addition to these advantages and disadvantages, the ability of the metrics to accurately convey competitiveness is paramount when deciding which metric to use. We argue that the existing competitiveness metrics - both comprehensive and non-comprehensive sets - can inaccurately rank-order technologies from the standpoint of system profitability. To show this, in the report we compare the implied rank order of a suite of stylized technologies in a simplified energy-only system with two demand periods. This simplified example is adapted from Joskow (2011), who used a similar conceptual system to highlight the shortcomings of LCOE. We expand this example to demonstrate how the various known metrics can result in varied and inconsistent rank-orderings with each other and, importantly, how they differ from the ranking using the system profitability metrics. In other words, how costs and system value are combined can influence the suggested degree of economic viability. In particular, by levelizing, or normalizing, the net value (or net cost) to a physical quantity rather than an economic value, the existing metrics can distort the suggested relative competitiveness. In contrast, the system profitability metrics are designed to only reflect economic value without normalizing to any physical quantity.

In fact, beyond the process of rank-ordering different technologies, the known metrics can also give a false impression of the degree of economic viability or technology progress toward viability over time and/or with innovation. For example, a change in a technology could increase its NVOC or NVOE but, at the same time, decrease its system profitability, thus demonstrating the potential pitfall of using the existing competitiveness metrics to track technology progress.

For these reasons, care is needed in ranking technologies or assessing their competitiveness using any of the metrics especially those that are incomplete or that might introduce bias by normalizing to a physical quantity. We argue that the system profitability metrics do not possess such inherent shortcomings; however, more work is needed to determine the conditions for which the system profitability metrics and the existing metrics agree or disagree. Furthermore, important limitations in the metrics - including the system profitability ones - and their quantifications as discussed below.

\footnotetext{
${ }^{6}$ Profitability-adjusted LCOE, which is a system profitability metric (see Section 3.5), also relies on a benchmark price.
} 


\section{Quantifying Metrics Using Electricity System Models}

The competitiveness metrics described above can be quantified using optimization-based models. These types of models are commonly used in electric system planning and operations, including for utility resource planning. Optimization-based capacity expansion models (CEMs) are particularly well-suited to quantify competitiveness metrics because they (1) consider both fixed and operating costs for technologies considered, (2) intrinsically reflect the long-run system needs and conditions, which is critically important given the sensitivity of technology system value to these factors and the long lives of many electric system technologies, (3) endogenously reflect the competition between technologies and their interactions with grid requirements to estimate service prices and provision, and (4) offer a consistent accounting framework to avoid double-counting or inconsistencies in assumptions when quantifying cost and value components. Of course, all models have limitations and fidelity is a critical consideration for CEMs given their broad scope.

We demonstrate this capability using the National Renewable Energy Laboratory (NREL) Regional Energy Deployment System (ReEDS) model, a long-term planning and dispatch model of the power system of the contiguous United States. Scenario estimates presented in the report are intended to illustrate how competitiveness metrics can be quantified; numerical values are illustrative only and can be sensitive to modeling assumptions and fidelity. ${ }^{7}$ Using this capability, we present how a model can be used to assess differences between technologies in terms of sources of cost (e.g., capital-intensive versus fuel-intensive costs) and system value (e.g., energy versus capacity versus ancillary service value). In fact, a model or some other means of estimating interactions between a technology and the system is needed to quantify system value, as system value is borne from these interactions.

In addition to estimating cost and system value components directly from the ReEDS modeling, competitiveness metrics - which are simply composed of the combination of these components - can also be derived through capacity expansion modeling. We demonstrate this capability and illustrate how doing so could support additional ways of using scenario results to provide deeper insights into technology viability. For example, we show how the metrics can be estimated for all potential U.S. wind sites modeled, thereby enabling an assessment of all options rather than focusing solely on the narrower set of deployment projections of any specific modeled scenario. ${ }^{8}$ In other words, this capability enables an examination of non-economic options in a scenario as well as the ones that model chooses in its optimization. The method can be extended beyond wind technologies. The report also presents additional potential applications from measuring competitiveness metrics using CEMs, including examinations of how competitiveness changes with increasing technology penetration and comparisons across technologies.

\footnotetext{
${ }^{7}$ Our analysis is not intended to evaluate market or modeling gaps - to determine whether any specific requirement (e.g., reserve margin) is set at the appropriate level and whether additional constraints should be considered (e.g., new ancillary service products). Instead, the purpose of our analysis is to assess how the different cost and value streams can be combined conceptually to assess overall competitiveness. The modeling assessment is simply used to support these concepts and demonstrate the capability to quantify the metrics.

${ }^{8}$ One caution is that as many of the competitiveness metrics are based on the marginal grid service prices, they do not directly inform the quantity to deploy.
} 


\section{Discussion and Limitations of All Metrics}

This report focuses on the conceptual aspects of competitiveness metrics and how to quantify them through modeling. In practice, several limitations and caveats exist when extending these concepts to their quantifications:

- First, although system value is needed to estimate competitiveness, it is intrinsically dependent on the system that one is assuming or modeling. Significant system uncertainties - in generation mix, fuel prices, and policies - exist over the lifetimes of many electric system technologies. Moreover, the sensitivity to system conditions can lead to large regional variations in relative competitiveness, further highlighting the nonuniversality of any quantification that relies on system value. Estimation or acknowledgement of these uncertainties and variations is needed.

- Second, system value components of the competitiveness metrics (including the system profitability metrics) rely on marginal grid service prices, which are sensitive to any finite penetration of the technology and can be especially sensitive for grid requirements with shallow markets. In other words, none of the competitiveness metrics (including system profitability metrics) directly informs how much of a technology to deploy.

- Third, our discussion focuses on system value and system profitability, which inherently refer to the perspective of a central system planner rather than a market participant, who might consider other metrics (including NPV) that are outside the scope of our assessment. System value can differ from market value. System value can also differ from societal value depending on the policies considered. By definition, externalitiesfactors that are not represented as system grid services (e.g., constraints for environmental or energy security requirements) - are not included within system value calculations that are based on marginal costs.

- Fourth, modeling fidelity is necessarily limited, and therefore, inaccurate estimates of system value are possible. This is especially noteworthy for grid requirements that address issues occurring over very short timescales (e.g., subhourly). Validation with higher-fidelity models might be required for improved confidence in results.

- Lastly, the complexities and system dependencies often require experienced and expert modeling to appropriately assess system value and competitiveness metrics. The metrics cannot replace the models as the latter are needed to generate the former.

In summary, in this report, we describe the applications, advantages, and disadvantages of a set of competitiveness metrics for electricity system technologies. Among the metrics discussed, we introduce a new set of "system profitability metrics" that enable robust economic comparisons of all types of technologies, regardless of the mixes of services that are provided. This is accomplished by putting all services on an equivalent monetary basis without normalizing or levelizing by a physical quantity, which can create distortions in the suggested competitiveness. We also demonstrate how the metrics, including the system profitability ones, can be quantified using capacity expansion models albeit with important limitations. 


\section{Table of Contents}

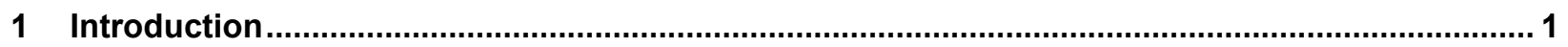

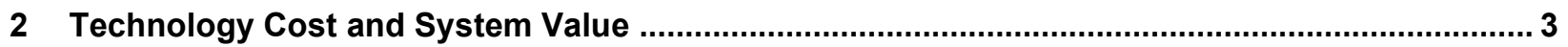

2.1 Sources of Cost and System Value............................................................................. 3

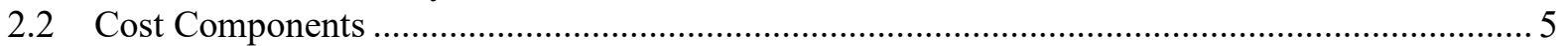

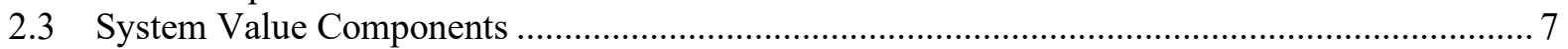

2.4 Context from Restructured U.S. Electricity Markets ........................................................ 10

3 Competitiveness Metrics: Definitions and Applications ...................................................... 12

3.1 Levelized Cost of Electricity ............................................................................... 14

3.2 Levelized Value of Electricity.............................................................................. 15

3.3 Net Value of Electricity and Net Value of Capacity ..................................................... 17

3.4 System LCOE...................................................................................................... 18

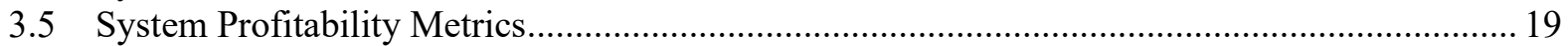

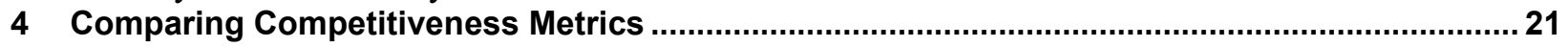

5 Quantifying Competitiveness Metrics ................................................................................ 25

5.1 Optimization-Based Capacity Expansion Models ............................................................. 26

5.2 Demonstration of Competitiveness Metrics Quantification ..............................................2 27

5.3 Limitations of Competitiveness Metrics and Their Quantifications .................................... 41

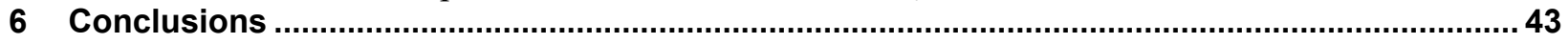

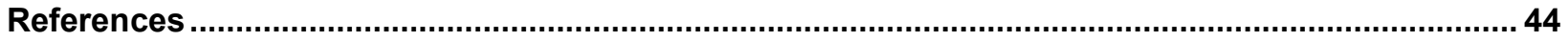

Appendix A: Metrics Equations ............................................................................................ 49

Appendix B: Application of System Profitability to Linear Program Solution Methods ................. 51 


\section{List of Figures}

Figure 1. Annual average (left) energy, (middle) capacity, and (right) ancillary service prices from two illustrative scenarios

Figure 2. Modeled energy prices by select time-slices in two sample model regions in lowa (left) and California (right)

Figure 3. Competitiveness metric wind resource curves in $\mathbf{2 0 3 0}$ from an illustrative scenario....... 32

Figure 4. LCOE, system LCOE, and profitability-adjusted LCOE onshore wind resource curves in

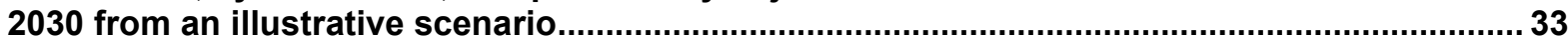

Figure 5. 2030 LCOE and LVOE estimates by component from an illustrative scenario ................... 35

Figure 6. Cross-technology comparison of 2030 NVOE (left), NVOC (middle), and system ROI (right) from an illustrative scenario

Figure 7. Cross-technology comparison of 2030 LCOE, system LCOE, and profitability-adjusted

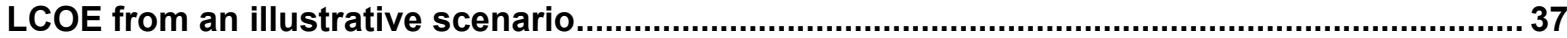

Figure 8. Value factor for onshore wind and utility PV as a function of penetration....................... 39

Figure 9. LCOE and profitability-adjusted LCOE for wind (left) and utility PV (right) over time and

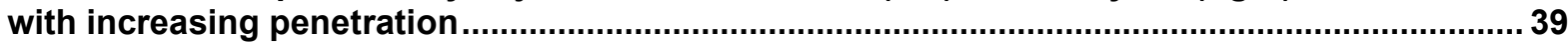

Figure 10. System ROI for onshore wind (left) and utility PV (right) over time with increasing penetration

\section{List of Tables}

Table ES-1. Competitiveness Metrics Reviewed........................................................................................ii

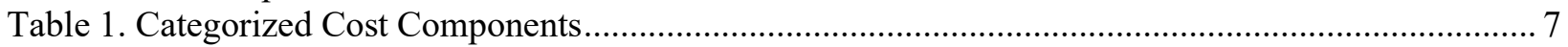

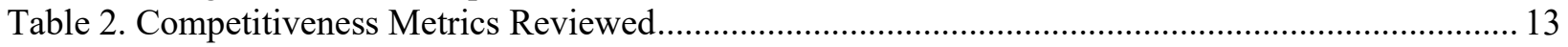

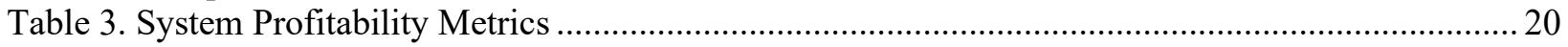

Table 4. Example Illustrating Differences Between Competitiveness Metrics ....................................... 23 


\section{Introduction}

The economic competitiveness of power generation technologies is a topic of much interest to diverse electric industry participants. Public and private technology R\&D managers need to understand how their technologies compare with others to guide research efforts and associated funding. Utility planners and regulators need to understand the ideal portfolio mix to meet reliability standards at least cost. Investors and consumers need to identify the most profitable or most efficient technology options. Analysts and researchers need to be able to accurately identify and succinctly communicate their findings to the above stakeholders as well as the general public. A wide spectrum of tools and data ranging in sophistication are used by these participants to assess competitiveness.

However, unlike many other commodities, where weighing economic competitiveness is relatively straightforward and determined to a large degree by a relatively uniform and stable price per unit, the competitiveness of electric supply options can be difficult to assess due to a combination of factors: (1) diverse and numerous grid services needed to reliably serve electricity consumers; (2) spatiotemporal variations in the cost to provide grid services caused by the challenges with transmitting and storing electricity; and (3) ever-evolving market and policy conditions, such as fuel prices and environmental regulations. Furthermore, the long lifetimes of most power sector assets require competitiveness assessments to consider these complexities in today's system as well as changes to the power system over several decades. One such change occurring in many U.S. regions today is the significant shifts in generation mix, particularly the increased reliance on natural-gas-fired generation and variable renewable energy (VRE) technologies. Furthermore, increasing penetration of VRE technologies makes the evaluation of technology competitiveness even more challenging due to their variability, uncertainty, and dispersed nature.

To handle these complications, researchers and electric utility planners often rely on complex models to identify least-cost portfolios that meet power system reliability, policy and legal, and, in some circumstances, societal welfare objectives (Hobbs 1995; Mills and Wiser 2013; Wilkerson, Larsen, and Barbose 2014). The class of models that have the primary purpose of identifying optimal portfolios is often referred to as capacity expansion models (CEMs), which considers a broad scope of both investment decisions (e.g., new technology costs, system need, and policy forecasts) and system operations (e.g., economic dispatch). Due to this broad scope, CEMs use reduced form representations to maintain computational tractability. For this reason, the portfolios identified by CEMs are often further evaluated using models with higher fidelity to better estimate power system economics at shorter operational (rather than investment) timescales and to assess a range of reliability-related metrics (e.g., AC power flow, frequency response, voltage stability). ${ }^{9}$ Although advancements to CEMs and increased application of linked models are continually under development and would help improve electric system planning, CEMs already provide the backbone of planning processes and future power system

\footnotetext{
${ }^{9}$ These higher-fidelity models are used to confirm or potentially alter the preferred portfolio identified by the CEMs in the context of utility planning. Higher-fidelity models are also used to operate restructured electricity markets or assess the market operations.
} 
research. And, conceptually, they provide a helpful framework - which we leverage in this report - for understanding technology cost, system value of the technology, and competitiveness.

Despite the use of CEMs and other tools to assess the economic competitiveness of different generation options, metrics to communicate the relative competitiveness remain rudimentary or poorly understood. For example, the levelized cost of electricity (LCOE) is a metric commonly used to compare generation technologies (Lazard 2017; NREL 2018), but LCOE measures only a technology's bus-bar cost, which includes the costs to build and operate the technology only up to the point of interconnection with the broader power grid, and does not capture the economic value that the asset provides to the grid. ${ }^{10} \mathrm{We}$ refer to the economic value of a technology to a system as the technology's system value. As we discuss in this report, an asset's value streams are borne out of interactions with the broader power grid and are derived by the provision of the various grid services. Nonetheless, LCOE can have certain advantages and appropriate applications even with its inherent limitations. For example, LCOEs are relatively straightforward to calculate without the need for power system models. To be clear, we are not aware of any current practice where LCOE, or any other similar simple metric, is used by itself to affect investment decisions; as described previously, utility planning and operations requires a wide range of complex models that go well beyond LCOE considerations. However, one or more metrics that more accurately express relative competitiveness could improve communications and education about generation technologies, especially to those who might not have access to the advanced tools.

The purpose of this report is to explore metrics that may be relevant for expressing the economic competitiveness of different electric sector options, including generators, storage, transmission, and other electric system assets. We define the metrics, describe their applications, and assess their limitations particularly when they might fail in conveying relative competitiveness of different options. To facilitate this exploration, we rely heavily on economic principles of marginal cost pricing, which is inherent in optimization-based CEMs. Our discussion is conceptually generalizable to any electricity system including potential future ones with different generation mixes and new grid services that are not currently compensated in electricity markets or commonly modeled by utility planners. ${ }^{11}$ In this report, we also demonstrate how the metrics can be measured using a specific CEM.

The competitiveness metrics explored in this report include LCOE, several metrics that have been introduced in the literature to overcome some of LCOE's shortcomings, and a new set of metrics that more directly applies standard economic metrics of profitability. We define and present applications of all metrics in the report. Many of the metrics from the literature have been introduced primarily in the context of examining the economics of VRE technologies, but, in principle, can be extended to other technologies as well. Similarly, the system profitabilitybased metrics that we introduce can also be applied to a full set of electric system assets. In this

\footnotetext{
${ }^{10}$ LCOE is expressed in units of dollars per unit electrical energy and, therefore, strictly speaking does capture a single source of value (energy). LCOE does not consider how the system might value the energy differently for different hours so it is only complete in the singular and non-realistic case where the only grid service is electricity and the price of electricity does not vary over time.

${ }^{11}$ The extensibility of our work is only in concept, and we do not intend to understate the potential technical challenges, including data availability and modeling fidelity, with understanding and modeling future energy systems.
} 
report, we do not exhaustively compare all metrics and their variations, but instead we aim to systematically compare the metrics including their definitions, uses, and limitations.

The objectives of this report are to discuss the technology cost and system value components that comprise competitiveness metrics (Section 2), describe and compare a set of metrics for electric sector technologies that incorporate these cost and value components (Sections 3 and 4), and demonstrate how the metrics can be quantified using a model (Section 5). Our focus is on the concepts rather than the quantification; future research is needed to provide the quantitative estimates for competitiveness metrics under a range of system conditions as well as to evaluate the grid requirements themselves. We discuss potential future research in Section 6.

\section{Technology Cost and System Value}

To assess competitiveness between electric system assets requires estimates of both their costs and system value, where system value refers to the economic value of the assets to the system. System value reflects the economic value (in dollar terms) that the technology offers to the system by directly providing electric sector services (or incurring additional service requirements). Costs, on the other hand, are expenditures that are required to provide the services in the first place. Although costs are relatively straightforward to estimate, system value estimates can be challenging because only in a technology's interactions with the broader system can its "value" be meaningfully assessed and, therefore, any value assessment is intrinsically system dependent. As we will present in Section 3, a competitiveness metric is defined by how it combines cost and system value components, and the completeness of the metric is determined by whether and how those various costs and values are considered.

Strictly speaking, sources of costs and values that one might consider depend on the perspective taken. Owners and investors consider the direct costs incurred and market revenues by their assets, which may or may not reflect all system value impacts of the asset appropriately. In contrast, utility or other electricity system planners might attempt to account for a morecomprehensive set of system value sources, irrespective of whether these sources can be explicitly compensated through real market interactions. In this report, we take the perspective of an idealized and centralized electricity system planner. ${ }^{12}$

\subsection{Sources of Cost and System Value}

A framework or methodology to assess technology cost and system value needs to be able to answer the following questions:

- How much of each service is provided by the different technology options?

- How much is each unit of service worth to the system at each location and time period?

- How much does it cost for each technology to provide the services?

\footnotetext{
12 The competitiveness metrics definitions shown later can be applied to multiple perspectives. While we explicitly take the electricity system planner perspective in identifying sources of cost and system value, the metrics comparison in this report may be applicable for more perspectives than just this central planner. Additional research is needed to explore different sources of cost and value, as well as the competitiveness metrics, for other perspectives, such as an individual merchant investor or a broad societal perspective.
} 
As explained in the following, we apply certain economic principles to the context of power system planning to answer these questions in a systematic fashion. In this context, grid requirements are designed to achieve certain system attributes, such as reliability, affordability, sustainability, and resiliency. ${ }^{13}$ Grid requirements are defined by both quantity ${ }^{14}$ (how much service is needed or the "market depth") and eligibility requirements ${ }^{15}$ (the ability of a technology to provide the service).

Consistent with a central electricity system planner perspective, system value attributed to a technology for each service is based on the marginal cost of the service. In competitive equilibrium, the marginal resource providing the service determines the marginal cost of that service. In this report, we regard price of a service as synonymous with marginal cost for that service. ${ }^{16}$ Note that the price for a unit of a grid service (e.g., megawatts of electricity during a specific hour) sets the marginal system value of all service units, including those provided by all (including inframarginal) assets. Assigning marginal system value to technologies based on marginal costs of services ensures all costs are recovered in equilibrium for each technology. ${ }^{17}$ Unless otherwise noted, within the planning perspective of this report - and consistent with the demonstration using capacity expansion models (Section 5) - marginal prices reflect the long run marginal costs, which consider both fixed (e.g., capital and fixed O\&M) and operating (e.g., fuel and variable O\&M) costs, as opposed to short run marginal costs that might only consider operating expenditures.

Given the importance of marginal cost pricing, an interpretation of the marginal cost might prove useful. The addition (or subtraction) of an asset to provide a service would displace (or increase the need for) the marginal resource providing that same service; therefore, the system value of that addition (or subtraction) should be the marginal cost of providing that service by the displaced (or added) resource. If only a single grid requirement exists, identifying the marginal resource and cost would be a simple exercise. However, given the interacting relationships between multiple services and technologies, an optimization model or similar sophisticated

\footnotetext{
${ }^{13}$ There can be multiple grid requirements designed for a single attribute and, similarly, a single requirement can support multiple attributes. For example, numerous grid requirements are designed and implemented to ensure a certain level of reliability. In this report, we do not assess the desirability of any attribute nor do we evaluate whether current system requirements are appropriate.

${ }^{14}$ Quantity requirements can be dependent on risk tolerance or the value of loss load. In other words, strictly speaking quantity requirements are not necessarily binary in nature, which differs from the "constraints" in optimization models (see Section 5). This aspect is outside the scope of our discussion but is important to recognize. ${ }^{15}$ Eligibility requirements can include technical requirements (e.g., ability to follow operator signals) or policybased ones (e.g., renewable mandates, market rules that specify technology eligibility). In current restructured markets, certain technologies may not be allowed to provide certain services even if they are technically capable of delivering those services. Even for a specific asset, eligibility can change depending on the state of the asset. For example, whether a generator unit is spinning can impact its eligibility to provide certain operating reserves. Similarly, eligibility for operating reserve provision is determined by whether the unit has headroom (in the case of "up" reserves) or room from its minimum generation point to turn down (in the case of "down" reserves). Eligibility can also be impacted by the existence of hardware and software systems, such as automatic generation control for traditional dispatchable generators and power electronics for inverter-based generators.

${ }^{16}$ Actual electricity markets may not compensate (or penalize) generators based on marginal cost pricing for all requirements. See Section 2.4 for more discussion.

${ }^{17}$ In actual restructured markets, other factors such as scarcity pricing, price caps, limited foresight, and bidding strategies can prevent this equilibrium condition from being achieved [e.g., the "missing money" problem (Hogan 2017; Milligan et al. 2017)].
} 
software is needed to consider the interactive effects between technologies and grid services (see Section 5). Because we base system value on marginal cost pricing, system value should be interpreted throughout this report as the marginal economic value of the asset to the system.

An asset's total system value is the product of the grid service prices and the amount of grid services provided by the asset, summed over all services. From this definition and in the context of a new investment decision, system value reflects the potential economic value from displacing or avoiding the cost of providing the services from other (marginal) assets. Avoided costs could include avoided operating costs from other generators or fixed costs for building new generation, storage, or transmission capacity. On the other hand, total costs for a new investment are simply the aggregate expenditures needed to build and operate the investment to provide the grid services. The definitions of system value and costs presented here enable a direct connection between technology valuation with total system cost. Specifically, the addition of an asset to a system would increase total system expenditures by the cost of building and operating the asset but would avoid the cost of other asset(s) to meet the grid service requirements for the system. The removal of an asset would have the opposite effect. In the limit of an infinitesimal change to an asset, defining system value based on the long run marginal costs makes this link possible.

\subsection{Cost Components}

Although there are important and complex research questions related to costs (e.g., why costs differ by region, how they might change over time through learning and research and development [R\&D], and how best to track and benchmark costs), these questions are outside the scope of our analysis. Instead, we identify metrics designed to assess competitiveness given a set of technology cost and performance assumptions. Overall, costs are often more straightforward to conceptualize than system value components, and therefore, we only briefly summarize the cost components.

Common sources of an asset's cost include capital, fixed operations and maintenance (FOM), variable operations and maintenance (VOM), and fuel costs. For the purposes of our discussion, capital costs include other costs related to the construction of the power plant equipment, such as financing costs, permitting fees, and land lease payments. Decommissioning costs could also be included if the evaluation period includes the full asset lifetime. We also include any costs for electrical equipment and transmission spur lines to interconnect the plant to the broader power system. ${ }^{18}$ Capital and operations and maintenance (O\&M) costs generally vary by location due to factors such as local labor costs, permitting and siting costs, infrastructure needs, and taxes and other state or local policies.

Costs can also vary by technological configuration examined, which can be influenced by the services targeted by that asset and the prices of the various services. As we discuss below, appropriately assessing an asset's competitiveness requires considering the system value of the asset in addition to its costs. An asset under a specific configuration might be more desirable even with higher costs because of the potential to generate greater system value or revenues with the asset. Examples include higher hub heights for wind turbines, larger inverter loading ratios

\footnotetext{
${ }^{18}$ Transmission expansion beyond these spur lines to connect multiple power plants and load centers are considered implicitly in the service prices. More generally, regional marginal prices for any service is affected by transmission losses, the capacity on the existing transmission network, and the cost of any new transmission.
} 
for photovoltaic (PV) plants, combined storage or hybrid configurations, and emissions controls for fossil technologies. When assessing technology competitiveness, additional or more-accurate cost estimates are needed to cover the range of specific technological configurations. Although our discussion and examples are focused on comparing technologies or locations, the competitiveness metrics we present are equally applicable for comparing different configurations of the same technology type.

Other sources of costs can include policy-related costs. In our accounting, tax credits are considered (negative) costs rather than (positive) values as they reflect revenues received by an asset that are largely independent of interactions with the rest of the system. ${ }^{19}$ An investment tax credit lowers the effective fixed cost independent of what services are provided by the asset. A production subsidy is more nuanced and can be impacted by (and can impact) the system, ${ }^{20}$ but under our convention, we assign these incentives as negative costs. An emissions price provides another example of a possible source of policy-related costs. Under our convention, an externally determined emissions price (e.g., a carbon tax) would be considered a cost (dependent only on the emissions from the asset) as the price is independent of the emissions from the remaining system. This is in contrast to an emissions cap or a renewable generation mandate, where prices are determined by the stringency of the requirement and the remaining portfolio, and thereby costs or values from these physical mandate-based policies would be categorized as (negative or positive) value streams to the asset.

Table 1 provides a non-exhaustive list of cost components often considered when evaluating competitiveness along with a brief discussion for each component.

\footnotetext{
${ }^{19}$ Alternate definitions of "cost" and "system value" are possible, including considering all positive impact on system cost as "cost" and all negative impact on system cost as "value". We have not explored the implications of these alternate definitions.

${ }^{20}$ For example, production subsidies could influence the economic dispatch and thereby alter prices. The amount of subsidy received can also be impacted by the amount of production, which depends on interactions with the system. Alternatively, policies or contracts might require a certain amount of production to receive the subsidies.

Curtailment is an example of how these interactions might yield different subsidy value.
} 
Table 1. Categorized Cost Components

\begin{tabular}{|c|c|c|}
\hline Component & Description and Nuances & Typical Units \\
\hline Capital Costs & $\begin{array}{l}\text { Capital costs include all the expenditures to build the power plant } \\
\text { or electric system asset. These expenditures include those for } \\
\text { equipment, labor, land, legal, and other soft costs. Capital costs } \\
\text { are often expressed as "overnight" costs or "all-in" installed costs, } \\
\text { where the latter includes the effect of construction financing and } \\
\text { other financing costs whereas the former does not. }\end{array}$ & $\$ / \mathrm{kW}$ \\
\hline $\begin{array}{l}\text { Fixed O\&M } \\
\text { (FOM) }\end{array}$ & $\begin{array}{l}\text { Plant O\&M costs that are needed irrespective of the amount of } \\
\text { electrical energy or other service produced by the power plant. } \\
\text { These costs can include capital equipment costs and labor costs. }\end{array}$ & \$/kW-year \\
\hline $\begin{array}{l}\text { Variable O\&M } \\
\text { (VOM) }\end{array}$ & $\begin{array}{l}\text { Plant O\&M costs, beyond FOM, that are needed for each unit of } \\
\text { electrical energy produced and can include labor, fuel, and } \\
\text { equipment costs (the latter of which through wear-and-tear on plant } \\
\text { equipment). It can be difficult to distinguish between FOM and } \\
\text { VOM. }\end{array}$ & $\$ / M W h$ \\
\hline Fuel Costs & $\begin{array}{l}\text { Fuel costs represent the amount of fuel needed to produce a unit } \\
\text { of electrical energy or other service. Fuel costs are affected by the } \\
\text { heat rate or efficiency of the power plant and the delivered price of } \\
\text { fuel. }\end{array}$ & $\$ / M W h$ \\
\hline $\begin{array}{l}\text { Spur Line } \\
\text { Costs }\end{array}$ & $\begin{array}{l}\text { Spur line costs represent the capital costs, primarily for } \\
\text { transmission equipment, needed to interconnect the plant to the } \\
\text { broader power system. We separate spur line costs from other } \\
\text { capital costs, but they are also often included in a single category. }\end{array}$ & $\$ / \mathrm{kW}$ \\
\hline Policy Costs & $\begin{array}{l}\text { Policy costs can include incentives (e.g., tax credits) or an external } \\
\text { price (e.g., carbon price) that are independent of interactions with } \\
\text { the rest of the system. }\end{array}$ & $\begin{array}{l}\$ / \mathrm{MWh}, \$ / \text { ton, } \\
\text { etc. }\end{array}$ \\
\hline
\end{tabular}

\subsection{System Value Components}

In contrast to the cost components, system value components are more difficult to assess as they are dependent on the system, the location within the system where the technology is interconnected, and how the system state changes over multiple timescales. System value represents the marginal economic benefit an asset provides to the system by delivering services to that system and avoiding costs for other assets. Given the central system planner perspective that we apply, the "avoided costs" can be equivalently interpreted as revenues a plant or potential asset might receive for delivering a set of services to the grid in an idealized market.

Two factors impact an asset's value for a given service. The first is the asset's actual (or estimated) amount of services provided. This quantity is limited by physical considerations as well as economic ones. An asset's physical ability to provide a service is determined by the eligibility requirement for the service as well as technical characteristics of the asset. For example, wind power production is constrained (on the upper end) by the wind speed at any given time. Another example is whether a power plant can ramp or start and stop quickly enough to provide flexibility or operating reserve services. In the general case, an asset's service provision is less than or equal to its capability to provide that same service. Within the capability limits, economics drive the optimal amount of service provision, where the economics are determined by the costs and capability limits of each and every option to provide the services. 
Determining this amount can be challenging because many technologies can provide multiple overlapping services and, in some cases, affect the requirements for the services themselves. For example, whether a power plant provides electricity or operating reserves in a given hour depends on the system state and opportunity costs for the power plant (Hummon et al. 2013). An important consideration - which particularly affects the long-run valuation of an asset-is the quantity of the requirement or market depth, which can have an effect on the rate of change of the service price as new providers enter the market.

The second factor that determines an asset's value is how much each unit of service is worth to the system. The price of a service is set by a suite of complex and interacting considerations, including system state, generator mix, and other market factors. In general, greater demand for or constraints on the supply of a service would yield higher prices. The unique aspects of electricity lead to service prices that can vary significantly by location and time. For example, electricity prices can fluctuate by multiple orders of magnitude between peak demand hours and off-peak periods. In our convention, the price of a service is determined by the marginal cost of providing that service. An abundance of available service providers can lead very low, perhaps even negative, prices.

The total monetary value of an asset is simply the product of these two factors - the service unit price and quantity of service provided-summed over all services. As aforementioned, prices are determined by what is avoided due to the integration of the new asset or, in the case of an existing asset, what is needed to replace the asset if it retired. Prices and, thus, the value of an asset depend on the type of service, location, and time that the service is needed. We define $P_{x, h}^{S}$ as the price for service $S$ in location $x$ during time period $h$ and $Q_{x, h}^{S, T}$ as the quantity (provision) from technology $T$ for the same service, location, and time period.

As system value is system dependent, the amount and composition of an asset's total system value can be subject to the grid requirements - which, in turn, are implicitly or explicitly designed to reach desired system attributes. As a result, unlike cost components, it can be more difficult to identify a core set of system value components. Nonetheless, because reliability is an attribute that many of the standards and grid services are intended to support, we can categorize system value components into four broad groups that are currently considered in the power systems in the United States: $:^{21}$

- Energy value is the system value of providing electricity demand requirements. ${ }^{22}$ In general, energy prices $\left(P_{x, h}^{E}\right)$ depend on location and time (e.g., hour) and are expressed by units of dollar per unit energy (e.g., $\$ / \mathrm{MWh})$. In long-run equilibrium, energy prices reflect both fixed (capital and fixed O\&M) and operating (fuel and variable O\&M) costs of marginal generators.

\footnotetext{
${ }^{21}$ The North American Electric Reliability Corporation (NERC) definition for reliable operation is "Operating the elements of the [Bulk-Power System] within equipment and electric system thermal, voltage, and stability limits so that instability, uncontrolled separation, or cascading failures of such system will not occur as a result of a sudden disturbance, including a cybersecurity incident, or unanticipated failure of system elements" (NERC 2018).

${ }^{22}$ In our analysis, we use "energy," "electrical energy," and "electricity" interchangeably, all having units of kilowatt-hours, megawatt-hours, or other energy unit.
} 
- Capacity value is affected by the type and cost of avoided firm capacity needed to ensure resource adequacy requirements, where resource adequacy is one aspect of reliability. Capacity value is sometimes implicitly considered as a part of energy value or even ancillary service value. Capacity prices $\left(P_{x}^{C}\right)$ depend on location but are intended to reflect the cost to provide long-term (e.g., annual or multi-year) system needs and, therefore, do not vary by hour. However, monthly or seasonal variations in the constituent components of capacity value (i.e., capacity credit and capacity prices) are often considered. Capacity prices are generally expressed in units of dollar per unit capacity over some long-term period (e.g., \$/kW-year).

- Ancillary service value is derived from the provision of a range of reserve products with operational (hourly or subhourly) timescales designed to support reliable grid operations. Ancillary services are also referred to as essential reliability services (Denholm, Sun, and Mai 2019). As with electricity prices, ancillary service prices $\left(P_{x, h}^{A S}\right)$ vary by location and time but are further complicated by the type of reserve, the diversity in requirements between jurisdictions, new and emerging requirements, and the challenges with calculating both the prices and provision as they require high-resolution modeling to estimate. Ancillary service prices are often expressed in units of dollar pers unit of available capacity over a specified time interval (e.g., \$/MW-h).

- Other value reflects the value of certain technology attributes that might be beneficial (or harmful) to the country, society or the environment beyond reliability-based grid services. Examples of such grid service products are renewable energy credits, which qualifying renewable energy assets can receive and load-serving entities can retire to meet renewable portfolio standards. In another example, emissions caps yield emission prices that can offer (negative) value for emitting technologies. Other potential elements that might fall within this category include water use, land use, economic development, energy security, public health and other social, environmental, or economic issues. ${ }^{23}$

Prices for different grid services can vary significantly in magnitude and have different units. However, the economic system value (in absolute dollar terms) is found by multiplying the grid service prices with the provision quantities and therefore can be compared between different grid services. An asset's total system value is simply the sum of these different system value components.

In addition to categorizing the system value components by different types of grid services, it is also useful to consider the meaning of different numerical regimes of system value for any given service. These regimes depend on both the grid service price and the quantity of service provided by the asset - both of which can be positive, zero, or negative. For the most part, system value is a positive quantity when an asset is providing a service to the system since the service provided by the asset avoids (positive) costs of other assets providing the same service.

\footnotetext{
${ }^{23}$ In this report, we do not focus on these other values, but note that for certain states and regions, they can have a significant effect on technology competitiveness and, therefore, are identified here for completeness. For many of these potential elements, markets do not yet exist.
} 
In another regime, an asset can have zero system value for a given service if it cannot or does not provide the service. An example of this includes the system value of nuclear power to provide regulating reserves due to technical limitations or regulatory requirements that prevent these generating units from operating flexibly. Another example is the capacity value of VRE at high penetrations where the marginal capacity credit of the VRE might be near zero meaning that VRE does not provide additional firm capacity services to serve resource adequacy requirements. Note that the lack of service provided does not mean that the asset incurs additional system costs, but simply that it does not provide system value (i.e., avoid system costs) for that service.

An asset may also have low or zero system value when the system has an excess grid services from the suite of possible providers. An example of this situation is when a system has capacity in excess of its planning reserve requirements resulting in the capacity value of any new resource to be zero. Another example is the energy value during curtailment events where excess generation conditions exist. In fact, grid service prices can even be negative during certain lowload and high-VRE availability (i.e., low net load) conditions where a combination of minimum generation and start-up costs for thermal plants and external policy drivers (e.g., the production tax credit) can lead to negative prices (Wiser et al. 2017).

Another situation where an asset might have negative system value for a grid service is when the installation or operation of the asset increases the grid service requirement. For example, VRE could increase operating reserve requirements and thereby have negative system value for these services. Another interpretation is that these assets are providing negative services to the system.

As suggested by the examples provided here, the varied numerical regimes for the system value components can result from varied and complex situations. While the underlying causes for the different situations are interesting and merit additional study, the conceptual framework to estimate system value introduced here - as the product of grid service prices and marginal costs - enables a consistent and comprehensive mechanism accounting method to determine system value across all possible regimes.

\subsection{Context from Restructured U.S. Electricity Markets}

In this report, we focus on the system value of a technology rather than its market value, where differences depend on how well specific market rules reveal system needs and pricing. Whether a power market comprehensively compensates technologies for different services is outside the scope of the analysis. From a modeling perspective, the system value represents the technology's contribution to every constraint or requirement (see Section 5). Of course, models are also not comprehensive and necessarily rely on simplifications that might not fully consider all system needs or technology capabilities. Our analysis is not intended to assess market or modeling gaps - to determine whether any specific requirement (e.g., reserve margin) is set at the appropriate level and whether additional constraints should be considered (e.g., new ancillary service products). Instead, the purpose of our analysis is to assess how the different cost and value streams can be combined conceptually to assess overall competitiveness.

Given this intent, it is useful to briefly relate our value categorization with those from current restructured U.S. electricity markets run by Regional Transmission Operators (RTOs) and Independent System Operators (ISOs). In U.S. restructured markets, energy prices are determined by locational marginal prices (LMPs), which reflect the cost of supplying the next 
megawatt of load at a specific pricing node during a specified period (e.g., hour, 15-minute, or 5minute). Even for energy services, multiple markets, including day-ahead and real-time markets, exist and are designed differently across regions. ${ }^{24}$ It is important to note that energy prices in CEMs differ from LMPs in an important way: when investment and dispatch decisions are cooptimized in a CEM, the energy price can account for new capital costs as well as operating costs whereas LMPs in energy-only or energy-portion of U.S. electricity markets are determined by bids that, in principle, represent variable O\&M, fuel, and other operating costs only. ${ }^{25}$

In addition to energy markets, some restructured power markets run capacity auctions to help ensure sufficient capacity is available over a specified multi-year period. The rules and specifics for capacity auctions can differ substantially between markets. For example, the power market run by the PJM Interconnection RTO includes an auction for capacity over a 3-year period while the Electric Reliability Council of Texas runs an "energy-only" market, where new capacity is incentivized in part during high electricity price hours and scarcity pricing, rather than a capacity auction. Other markets, such as the California ISO and the Southwest Power Pool, have resource adequacy requirements that mandate load serving entities participating in the markets to selfsupply capacity or use bilateral contracts to procure capacity. Byers, Levin, and Botterud (2018) reviews issues around U.S. capacity market design in the context of increasing renewable energy.

RTOs and ISOs currently have a spectrum of ancillary service markets, requirements, and nomenclature (Ela et al. 2014; Zhou, Levin, and Conzelmann 2016; Denholm, Sun, and Mai 2019). Ancillary services, however, can be classified — and are often modeled — using a few general reserve types: Regulation reserves are established to manage frequency deviations during regular fluctuating imbalances between supply and demand or during an event where system frequency deviates from standard levels (e.g., $60 \mathrm{Hertz}$ ). Contingency (spinning) reserves are designed to manage frequency declines caused by unexpected generator or transmission outages. Replacement (non-spin) reserves are intended to take over for the contingency reserve providers subsequent to a defined period after the contingency event. Additionally, a variety of newer operating reserves, which we refer to as flexibility reserves, have been designed to manage increased variability (e.g., ramping) and uncertainty (e.g., forecast errors) associated with variable renewable technologies. Ideally, ancillary service markets and energy markets are cooptimized. Because of this co-optimization, the diversity of different ancillary services, the short timescales for these services, and the numerous technology characteristics that determine whether, how much, and what cost to provide a service, ancillary service prices and provision can be very difficult to estimate and generalize (Hummon et al. 2013). This is true for current systems and might apply even more so to future systems, where markets for other ancillary services (e.g., black start, voltage support, primary frequency response) may emerge.

A subset of these grid services is mandated rather than procured as market products in part due to a combination of their localized requirements, the relatively small amount of services needed, and the administrative costs to run a market. Although no markets currently exist for these services in the United States, in some instances the costs to provide the services are recovered through non-market mechanisms. In general, the existence of bilateral contracts, non-economic

\footnotetext{
${ }^{24}$ Day-ahead markets are often used to set most unit-commitment decisions while real-time markets might have different economic dispatch results using more up-to-date information.

${ }^{25}$ However, scarcity pricing, price caps, bilateral contracts, complex price formation rules, and other factors may cause LMPs to differ from marginal operating costs.
} 
dispatch, make-whole payments, and reliability must run requirements that alter dispatch, market prices, and generator revenues can further complicate technology valuations in current market settings.

The generalized description of current U.S. electricity markets is used to provide context to our value categories - energy value, capacity value, ancillary service value, and other value — but it is beyond the scope of our analysis to comprehensively describe or evaluate the existing markets. In addition, although we use examples from current restructured electricity markets to provide this context, many of the same principles are used for utility planning and operations in traditionally vertically integrated regions. The remainder of the report focuses on how the various cost and value streams can be combined to define competitiveness metrics and not on specific definitions for any single component.

\section{Competitiveness Metrics: Definitions and Applications}

The metrics that we evaluate in this report include LCOE, levelized value of electricity (LVOE), net value of electricity (NVOE), net value of capacity (NVOC), system LCOE, and system profitability metrics. We categorize these metrics into three groups: the first group of known metrics includes LCOE and LVOE, neither of which comprehensively include all sources of costs and value together; the second group includes NVOE, NVOC, and system LCOE, which have all been introduced previously in the literature and comprehensively consider both costs and system value through their differences; and the last group includes system profitability metrics, which, to our knowledge, are new metrics applied in the context of assessing the competitiveness of electric system assets. Table 1 (next page) provides short definitions for these metrics, and the following subsections provide more complete definitions, highlight alternative definitions or variations from the literature, discuss applications, and note scope and other limitations. The mathematical expressions for the metrics are summarized in Appendix A.

All metrics rely on discounting future costs and system value such that all economic measures can be compared on a present value basis. Appendix A shows the mathematical expressions for the discount factors and present value calculations. For simplicity, the expressions show a constant and uniform discount rate and evaluation period for all years and technologies. More complex treatment for present value calculations may be appropriate but are outside the scope of our analysis. However, even as these complexities could impact the quantitative estimates for the metrics, they do not affect our conceptual discussion of the metrics themselves.

Our discussion focuses on the specific context of the economic viability of new assets, but the metrics can also be applied to other decisions (e.g., upgrade and retirement decisions of existing assets). This is not an exhaustive list of metrics for assessment of economic competitiveness of electricity generation technologies. We focus on normalized metrics that can be used to convey competitiveness between classes of technologies, rather than for discrete investment options. In particular, none of the metrics evaluated speaks to the magnitude of investment. Notably absent from our scope are un-normalized metrics like net present value (NPV), which are commonly used in finance and investment decisions. In the following subsections, we synthesize the key 
references and most salient points therein, but we refer the reader to the cited references for additional detail and for related literature. ${ }^{26}$

Table 2. Competitiveness Metrics Reviewed

\begin{tabular}{|c|c|c|c|}
\hline & Metric & $\begin{array}{l}\text { Conceptual Expression } \\
\text { [typical units] }\end{array}$ & Definition \\
\hline \multirow{2}{*}{ 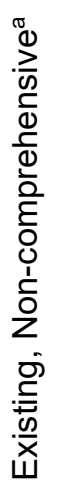 } & $\begin{array}{l}\text { Levelized } \\
\text { Cost of } \\
\text { Electricity } \\
\text { (LCOE) }\end{array}$ & $\begin{array}{l}\text { Cost/Energy } \\
\text { [\$/MWh] }\end{array}$ & $\begin{array}{l}\text { LCOE is the cost that, if assigned to every unit of } \\
\text { electricity by an asset over an evaluation period, } \\
\text { will equal the total costs during that same period } \\
\text { when discounted to the base year. }\end{array}$ \\
\hline & $\begin{array}{l}\text { Levelized } \\
\text { Value of } \\
\text { Electricity } \\
\text { (LVOE) }\end{array}$ & $\begin{array}{l}\text { Value/Energy } \\
\text { [\$/MWh] }\end{array}$ & $\begin{array}{l}\text { LVOE is the value that, if assigned to every unit } \\
\text { of electricity generated by an asset over an } \\
\text { evaluation period, will equal its total system value } \\
\text { during that same period when discounted to the } \\
\text { base year. }\end{array}$ \\
\hline \multirow{3}{*}{ 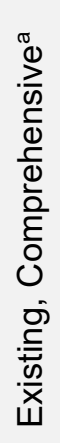 } & $\begin{array}{l}\text { Net Value of } \\
\text { Electricity } \\
\text { (NVOE) }\end{array}$ & $\begin{array}{l}\text { (Value - Cost)/Energy } \\
{[\$ / \mathrm{MWh}]}\end{array}$ & $\begin{array}{l}\text { NVOE is the difference between LVOE } \\
\text { and LCOE. }\end{array}$ \\
\hline & $\begin{array}{l}\text { Net Value of } \\
\text { Capacity } \\
\text { (NVOC) }\end{array}$ & $\begin{array}{l}\text { (Value - Cost)/Capacity } \\
{[\$ / k W-y r]}\end{array}$ & $\begin{array}{l}\text { NVOC is the difference in an asset's annual } \\
\text { system value and its annualized costs, divided by } \\
\text { the installed capacity of the asset. }\end{array}$ \\
\hline & $\begin{array}{l}\text { System } \\
\text { LCOE }\end{array}$ & $\begin{array}{l}\text { (Cost - Value)/Energy + } \\
\text { Benchmark Price } \\
{[\$ / \mathrm{MWh}]}\end{array}$ & $\begin{array}{l}\text { System LCOE is the negative of NVOE but } \\
\text { further adjusted by a benchmark price. }{ }^{b}\end{array}$ \\
\hline 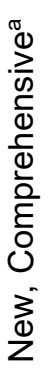 & $\begin{array}{l}\text { System } \\
\text { Profitability }\end{array}$ & $\begin{array}{l}\mathrm{f}(\text { Value/Cost }) \\
\text { [unitless] }\end{array}$ & $\begin{array}{l}\text { System profitability metrics are linear functions of } \\
\text { the ratio between total system value and cost. } \\
\text { Examples include system benefit-cost ratio } \\
\text { (value/cost), system return on investment } \\
\text { (value/cost - 1), and system profit margin ( } 1 \text { - } \\
\text { cost/value). }\end{array}$ \\
\hline
\end{tabular}

${ }^{a}$ The metrics are grouped according to whether they are existing or new metrics and whether they can comprehensively consider both costs and system value.

${ }^{\mathrm{b}}$ The benchmark price can be arbitrarily chosen, although it should be consistent across technologies for a meaningful comparison. Benchmark prices can vary by scenario and year. Various benchmark prices have been suggested in the literature, including the annual average of hourly marginal electricity prices or an average price in a no-renewables system.

\footnotetext{
${ }^{26}$ Wiser et al. (2017) provides a summary of the literature for the known metrics (LVOE, NVOE, NVOC, and system LCOE), but varied terms are used in the literature.
} 


\subsection{Levelized Cost of Electricity}

LCOE is a well-known and often-used metric for comparing electric generation technologies (Lazard 2017; NREL 2018). As defined in Table 1, LCOE is the cost that, if applied to every unit of electrical energy over a specified period (e.g., plant lifetime or contract term), will equal the total costs over that same period on a present value basis. LCOE calculations range from relatively simple expressions to fairly complex ones. ${ }^{27} \mathrm{LCOE}$ is often expressed as the present value of all costs (fixed and operating) divided by the present value of electrical energy production over the same period. Because it, in principle, considers all sources of cost —capital costs, fixed and variable O\&M costs, and fuel costs - and potential changes in electricity production over time, LCOE enables a comparison of technologies with different characteristics (e.g., fuel-intensive versus capital-intensive technologies).

As we discuss in Section 1, although LCOE is not used to inform investment decisions and is not itself directly input in advanced electric sector capacity expansion models that inform utility planning or procurement decisions, LCOE is commonly used to communicate technology comparisons (e.g., Lazard 2017; NREL 2018). This use can be appropriate to track the cost and performance progress of a single technology over time or to compare technologies that operate similarly and that primarily provide energy services. The latter use is most appropriate for situations when the electricity price has limited intra- and inter-annual variability.

We emphasize the limited system dependency of LCOE in this report to highlight differences between it and the other metrics, but several factors should be considered when using or comparing LCOEs. LCOEs can be highly sensitive to location due to variations in resource quality (e.g., wind speed or solar irradiance), fuel prices, or capital and labor costs. When comparing LCOEs, it is worth acknowledging, for example, whether the average or best sites are represented. The scope of the cost components included in LCOE estimates can also be material. For example, whether LCOEs include the cost of additional transmission infrastructure upgrades, including spur lines to interconnect the plant, can have a measurable impact for resource-limited technologies. LCOEs can also differ if using bottom-up cost estimates or are inferred from market-based data (Feldman et al. 2012; Bolinger and Seel 2018). Other considerations with LCOE include whether incentives are included, whether its expressed in real or nominal dollars, and the underlying assumptions for cost, performance, finance, and evaluation period. ${ }^{28}$ These

\footnotetext{
${ }^{27}$ In its most basic form, LCOE is defined by the following equation: $\sum_{t}^{Y} \frac{L C O E * Q_{t}}{(1+d)^{t}}=\sum_{t}^{Y} \frac{C_{t}}{(1+d)^{t}}$, where $t$ is the year starting at $\mathrm{t}=0, \mathrm{Y}$ is the evaluation period, $\mathrm{d}$ is the discount rate, $\mathrm{Q}_{\mathrm{t}}$ is the amount of electricity produced in year $\mathrm{t}$, and $C_{t}$ is the total expenditures incurred in year t. Short, Packey, and Holt (1995) offer a detailed discussion of LCOE calculations and related considerations. The System Advisor Model (Blair et al. 2018) offers multiple methods and parameter options to calculate LCOE. Many other financial pro forma tools are used by analysts to calculate LCOEs.

${ }^{28}$ One common and, perhaps, underappreciated aspect to consider in comparing LCOE estimates or comparing LCOEs of different technologies is the evaluation period. The appropriate evaluation period will depend on the perspective, especially when comparing assets that have very different physical lifetimes or for assets whose ownership may change hands multiple times. For example, the economic lifetime is relevant for certain investments but may not reflect the relative societal impacts where the physical lifetime may be more appropriate (Jenkin et al. 2019). The interpretation of different evaluation periods and how the choice of evaluation period might impact technology cost and system value are outside the scope of this report.
} 
important considerations are outside the scope of this report but can measurably impact LCOE estimates.

The above considerations can add complications to calculating and interpreting LCOE comparisons. Notwithstanding these complications, LCOE remains a relatively straightforward metric to calculate compared with the others that rely not only on considerations about the technology of interest but also on the broader system. ${ }^{29}$ The ease of calculating LCOE can lead to temptations to extend its application beyond appropriate uses and can give false impressions about technologies. In fact, the LCOE metric has three inherent limitations that make it imperfect for conveying competitiveness for a robust set of electric system technologies and conditions. First, LCOE only covers energy services and, therefore, is inappropriate for evaluating technologies for which energy is not the primary service provided (e.g., flywheels or shortduration storage technologies that are used for frequency regulation). Second, even restricting to energy services, LCOE does not account for time or locational variations in system need for energy. Comparing the LCOEs of a peaking unit with a plant that operates in "baseload" fashion does not reveal much about the competitiveness between the two. The third shortcoming of LCOE, which is an extension of the second, is that although energy units are in the denominator for LCOE, LCOE reveals nothing about the system value of those energy services in monetary terms. As a result of these established shortcomings of LCOE, metrics that consider system value have been introduced to supplement or replace LCOE.

\subsection{Levelized Value of Electricity}

The omission of any considerations of an asset's value to the system is the core limitation of the LCOE metric. Recognizing this limitation, many have calculated "system value" metrics that estimate an asset's monetary value in providing energy and other grid services to the system (EIA 2018a; Wiser et al. 2017; Hirth and Müller 2016; Mills and Wiser 2012; Mills and Wiser 2014; Dalla Riva, Hethey, and Vìtina 2017; Lamont 2008). Unlike with LCOE, no consistent form or term exists for a system value measure. For example, EIA (2018b) refers to a levelized avoided cost of energy (LACE) as "a measure of what it would cost the grid to generate the electricity that would be displaced by a new generation project." For our purposes, we define a levelized value of electricity (LVOE) metric as an asset's total present value of system value through providing all services divided by the present value of electrical energy produced by the

\footnotetext{
${ }^{29}$ Strictly speaking, an asset's LCOE can have some system dependencies. For example, an asset's utilization can be impacted by the system that it is interconnected with (e.g., dispatch of thermal generators and curtailment for VREs). One way to ensure consistency is to calculate LCOEs using their maximum possible utilization and consider actual utilization within the value side of the ledger. We apply such an accounting convention in our modeling for VRE curtailment (Section 5).
} 
asset. ${ }^{30}$ This form, of course, is similar to LCOE. ${ }^{31}$ However, unlike LCOE, it considers the economic system value of the asset rather than the expenditures to build and operate the asset.

An inconsistency that exists in the system value literature is the number and types of grid services included in a system value estimate. Energy value is included in many system value measures, but whether capacity value or other grid services are included can vary. In principle, and as we discuss in Section 2, system value can include all grid services and can be decomposed into groups of grid services. In this report, LVOE includes the system value from all grid services and those value streams are levelized by electrical energy. LVOE is expressed in units of dollars per megawatt-hour.

Another measure related to system value or LVOE is "value factor," which has been introduced in the literature primarily in the context of declining VRE value with penetration (Mills and Wiser 2012; Hirth 2013; Hirth and Müller 2016; Wiser et al. 2017). Typically, an asset's value factor is defined as the ratio of its LVOE to the LVOE of a hypothetical "flat block" technology that has a $24 \times 7$ or truly "baseload" electricity generation profile, ${ }^{32}$ but for the purposes of this report, we define value factor of an asset more broadly as the ratio of its LVOE to a system "benchmark price" that is averaged over space and time. Benchmark price could correspond to the LVOE of a flat block, or it could resemble more of a total wholesale price to provide reliable electricity by including resource adequacy and ancillary service prices, for example, which are not included in the flat block definition. Regardless of how benchmark price is defined, it is important to maintain a consistent definition when comparing value factors across technology options.

Value factor can show how the system value of an asset with a certain temporal production profile compares with how the grid services are valued on average by the system over a year or the lifetime of the asset. For example, at low penetrations, solar profiles are closely correlated with demand (and price) profiles, and therefore, solar technologies can have relatively high value factors. In contrast, wind technologies with a greater share of off-peak production can have lower value factors. However, value factors can change with VRE penetration due to the correlations in production profiles between different renewable energy power plants and locations. Despite the focus on VRE value factor in the literature, value factor can be calculated for any technology if its dispatch and prices are known or assumed.

\footnotetext{
${ }^{30}$ Our LVOE metric differs from the LVOE metric introduced by Heuberger et al. (2016), where the latter is more similar to our NVOC (Section 3.4). In contrast, Heuberger et al. (2017) uses "system value" to describe a similar "net" metric. Needless to say, there is a lack of consensus on what we call LVOE, but we define and refer to LVOE in the way described so that it is most similar to LCOE in form. We include LVOE as a competitiveness metric, but do not mean to suggest that others have used or presented LVOE-like metrics directly to analyze competitiveness. In fact, LVOE and similar measures of system value have been raised to highlight how LCOE does not accurately convey competitiveness.

${ }^{31}$ Algebraically, this form means that LVOE is the value per unit electrical energy that, if assigned to every unit of electrical energy produced by the asset over an analysis period, will equal the total value of the asset over the same period on a present value basis. LVOE is defined by the following equation: $\sum_{t}^{Y} \frac{L V O E * Q_{t}}{(1+d)^{t}}=\sum_{t}^{Y} \frac{V_{t}}{(1+d)^{t}}$, where $\mathrm{t}$ is the year starting at $t=0, Y$ is the evaluation period, $d$ is the discount rate, $Q_{t}$ is the amount of electrical energy produced in year $t$, and $V_{t}$ is the total revenues received in year $t$.

${ }^{32}$ The flat block is defined in different ways by different sources. Specific discrepancies are the services that the flat block provides and whether the flat block is located at a particular location or is distributed spatially.
} 
When using value factor with the "benchmark price" concept above, it is important to note that benchmark price can change over time and is itself system dependent. ${ }^{33}$ As a result, value factor is not a direct measure of LVOE. For example, an asset with a declining value factor can still have stable or increasing LVOE if energy prices are increasing sufficiently over the same period. Nonetheless, value factor provides a mechanism to understand the impacts of certain technology attributes (e.g., temporal profiles) compared with the average system prices.

Both LVOE and value factor are dependent on the system state as an asset's system value is estimated from the interaction of the asset with the broader system. Therefore, modeling is often required to simulate these interactions and derive prices and provisions needed to calculate LVOE and value factor. Market data and price-taker analyses can also be used for such estimates; however, it is also important to note that system value is distinct from market value as the latter is subject to specific market rules that may not fully reflect system needs and prices. As metrics, LVOE and value factor suffer from the same basic limitation as LCOE: While LCOE omits economic value for providing grid services, LVOE and value factor omit the costs to provide those services and, therefore, are incomplete for determining relative competitiveness.

\subsection{Net Value of Electricity and Net Value of Capacity}

The omission of system value in LCOE has motivated the development of competitiveness metrics that more-completely incorporate costs and value. ${ }^{34}$ To this end, net value metrics have been introduced. These metrics use the difference between a measure of value and a measure of cost to assess competitiveness, where the gap to viability scales with this difference. We highlight two specific forms of this metric: net value of electricity (NVOE) and net value of capacity (NVOC). NVOE is simply the difference between LVOE and LCOE, and it is therefore expressed in units of dollars per unit electrical energy. NVOC is similar to NVOE, except instead of levelizing the net value by electrical energy, it is defined as the annualized net value by the installed capacity. In this form, NVOC is expressed in units of dollars per capacity per year. Note that both NVOE and NVOE can include multiple or all sources of system value (e.g., energy, capacity, A/S value), but differs in how this economic value (in dollars) is levelized or normalized (by energy or capacity).

While we present two specific forms of net value, many variants of these metrics exist with variations in sign and units. For example, Wiser et al. (2017) refers to "LCOE net of system value," which is equivalent to our NVOE metric except with the opposite sign, and EIA (2018b) compares LCOE and LACE. In other publications, very similar metrics to NVOC have been introduced and labeled "profit" (Joskow 2011), "levelized value of electricity" (Heuberger et al. 2016), and "system value" (Heuberger et al. 2017). Monitoring Analytics (2018) refers to a "net revenue" measure that is also similar to NVOC, but instead of the difference between total system value and total costs, it measures the difference between annualized fixed costs and net operational value, where net operational value represents the operational revenue minus variable costs. Despite these variations and lack of consensus in the terms used, because these metrics are

\footnotetext{
${ }^{33}$ We discuss benchmark prices in greater detail in Sections 3.4 and 3.5.

${ }^{34}$ LVOE is incomplete as it does not capture technology cost; however, because LVOE is not commonly used in the literature, it has not provided the motivation for the other metrics in the way that LCOE has.
} 
based on the difference between value and cost and normalized by a physical unit, they share common conceptual limitations for expressing competitiveness, as we discuss in Section 4.

For our specific forms of net value, a technology is economically viable (from a system perspective) when its net value is greater than or equal to zero. Furthermore, the net value metrics are intended to inform the degree of economic viability (per unit of that technology's capacity or electrical energy). For example, the intention with the net value metrics is that a technology with an NVOE of $-\$ 10 /$ MWh is closer to viability than one with an NVOE of $\$ 20 / \mathrm{MWh}$. If this is correct, the net value metrics can also be used to inform technology progress over time or through R\&D advancements. We argue in Section 4, however, that this may not be the case. In fact, different variants of net value (including between NVOE and NVOC) can yield different conclusions about relative technology competitiveness and the degree of competitiveness.

\subsection{System LCOE}

System LCOE is a metric first introduced by Ueckerdt et al. (2013) primarily to express and estimate "integration costs" of VRE technologies. ${ }^{35}$ Using our notation, the general form of system LCOE is equivalent to Benchmark Price + LCOE - LVOE. Obviously, this form is closely related to $\mathrm{NVOE}^{36}$ with the exception of the sign difference and the inclusion of a benchmark price. ${ }^{37}$ With this form, it is clear that the benchmark price determines the threshold when a technology is economically viable; a system LCOE greater than the benchmark price suggests that the technology is not viable. Because of this, knowing the benchmark price is needed to fully interpret system LCOE measures; thereby adding additional complexity.

Conceptually, the benchmark price can be arbitrarily chosen or calculated using various methods. In fact, multiple variations of benchmark prices have been introduced in the literature. In Ueckerdt et al. (2013), the benchmark price is the total cost of a system without any VRE divided by the electricity demand of the system. They suggest that the difference between VRE's system LCOE and LCOE (equal to Benchmark Price - LVOE) is a measure of that VRE's integration costs. Hirth, Ueckerdt, and Edenhofer (2015) define the benchmark price as the annual-average marginal price of electricity of the system in question (with variable renewables). Müller et al. (2018) discuss issues around the choice of the benchmark price. It is important to note that the benchmark price can change over time and can be system dependent. As a result, when interpreting system LCOE values, one must recognize the choice of benchmark price, which often contains these system and time dependencies.

Other variations of system LCOE exist in the literature. Wiser et al. (2017) provide further discussion of system LCOE and different methods to calculate the metric. Reichenberg et al. (2018) introduce a "marginal system LCOE" metric that is closely related to the others cited. The International Energy Agency (2018) presents a "value-adjusted LCOE" metric that is also

\footnotetext{
${ }^{35}$ Integration cost can mean different things to different people. Our use here is based on how Ueckerdt et al. (2013) and Hirth et al. (2015) have used it. Others define integration costs only on the operational impact that VREs might induce, such as increased operating reserve requirements.

${ }^{36}$ System LCOE = Benchmark Price - NVOE.

${ }^{37} \mathrm{We}$ introduced the concept of benchmark price while defining value factor in Section 3.2. Note that the benchmark prices used in literature for value factor calculations may not correspond to those used for system LCOE calculations.
} 
conceptually closely related to system LCOE. For this metric, adjustments for three decomposed sources of value - energy, capacity, and flexibility - are used to modify the LCOE. These adjustments are based on differences between a technology's value and a benchmark value much in the same way as in system LCOE. However, the value-adjusted LCOE metric is designed to capture differences in energy, capacity, and flexibility values only and is not meant to comprehensively capture differences for all potential sources of costs and value.

For our purposes, all variations of system LCOE essentially take the same form of a benchmark price minus NVOE and, thus, do not substantially differ in their ability to robustly convey technology competitiveness. As with NVOE, this form considers both system value and technology costs and is therefore more complete than LCOE and LVOE.

\subsection{System Profitability Metrics}

System profitability metrics are those that directly apply standard metrics in the economics and business literature for measuring the economic efficiency of an investment, including benefitcost ratio (BCR), return on investment (ROI), and profit margin. Table 3 defines these concepts and metrics as applied to system value and cost of electricity system technologies. Although the system profitability metrics can take various forms, they are all equivalent in assessing economic competitiveness and all have the same unifying form of being a function of the ratio between system value and cost. ${ }^{38}$ Our application of system profitability metrics to evaluate the economic competitiveness of electric system technologies is motivated by Joskow (2011), who provides a compelling argument for viewing competitiveness through the lens of profitability:

[T]he economics of all generating technologies, both intermittent and dispatchable, can be evaluated based on the expected market value of the electricity that they will supply, their total life-cycle costs, and their associated expected profitability. Such an analysis would reflect the actual expected production profiles of dispatchable and intermittent technologies, the value of electricity supplied at different times, and other costs of intermittency associated with reliable network integration. This is exactly the way investors in merchant generating plants evaluate whether or not to invest. (page 241)

Joskow (2011) applies this argument to highlight the limitations of LCOE and suggests that a metric similar to NVOC would be an improvement. We build on the conceptual foundation

\footnotetext{
${ }^{38}$ These system profitability metrics are closely related to a suite of other commonly used metrics. In this report, we focus on normalized metrics that allow for meaningful comparisons of the competitiveness of classes of technologies (as opposed to specific projects) from a system perspective, but it is important to understand that other financial metrics can result in different rank-ordering of investment opportunities. Which metric is most appropriate is contingent on the context of the investment decision. For example, benefit-cost ratio and profitability index can differ on whether they are normalized against the total present-value costs or just the initial investment amount, therefore one consideration to weigh when choosing between the two is whether the investor is facing a capital budget constraint. As another example, these types of normalized metrics can make small, high-return projects seem very competitive, so practicing investors often complement them with NPV or other non-normalized metrics when comparing sets of projects. To see examples where these suites of financial metrics have been applied to the power sector, see CPUC (2001) (evaluation of electricity system demand-side programs), Short, Packey, and Holt (1995) (evaluation of energy efficiency and renewable energy technologies), and Drury, Denholm, and Margolis (2011) (evaluation of residential and commercial solar photovoltaics).
} 
established by Joskow (2011) to introduce the system profitability metrics rather than the NVOC-like metric.

Table 3 summarizes the conceptual expressions and descriptions of the various system profitability metrics. As noted previously, the metrics all are functions of the ratio between total system value and total cost, and thereby can be related to the prior metrics as well. For example, system BCR can be calculated and expressed as LVOE divided by LCOE. However, there is no need to levelize by unit of electrical energy or other physical unit to calculate system profitability; the same dimensionless system BCR would be found if one calculated total present value of system value (in dollar units) divided by total present value cost (also in dollar units). The lack of need to levelize or normalize the system profitability metrics by a physical unit reveals that the metrics are intrinsically agnostic to the sources of system value and technology costs. ${ }^{39}$ Through being purely economic and not restricted to any one electricity sector service or parameter, system profitability metrics enable assessment of all electricity sector investment options on equal footing, whether they be electricity generators primarily providing energy value to the system, peaking capacity resources providing little to no electricity, storage technologies arbitraging electricity (and losing it on net), demand-response programs, or transmission infrastructure investments.

Table 3. System Profitability Metrics

\begin{tabular}{|c|c|c|}
\hline Metric & $\begin{array}{l}\text { Conceptual } \\
\text { Expression } \\
\text { [typical units] }\end{array}$ & Description \\
\hline $\begin{array}{l}\text { System Benefit-Cost Ratio } \\
\text { (BCR) }\end{array}$ & $\begin{array}{l}\text { Value/Cost } \\
\text { [unitless] }\end{array}$ & $\begin{array}{l}\text { Present value of system value divided by } \\
\text { present value of system cost; greater than } \\
\text { or equal to } 1 \text { for economic viability }\end{array}$ \\
\hline $\begin{array}{l}\text { System Return on Investment } \\
\left(^{\text {ROI })^{a}}\right.\end{array}$ & $\begin{array}{l}\text { (Value/Cost) - } 1 \\
\text { [unitless] }\end{array}$ & $\begin{array}{l}\text { Greater than or equal to } 0 \text { for economic } \\
\text { viability }\end{array}$ \\
\hline System Profit Margin & $\begin{array}{l}1 \text { - (Cost/Value) } \\
\text { [unitless] }\end{array}$ & $\begin{array}{l}\text { Greater than or equal to } 0 \text { for economic } \\
\text { viability }\end{array}$ \\
\hline Profitability-Adjusted LCOE & $\begin{array}{l}\text { Benchmark Price } X \\
\text { (Cost/Value) } \\
{[\$ / \mathrm{MWh}]^{\mathrm{b}}}\end{array}$ & $\begin{array}{l}\text { The profitability-adjusted LCOE is the } \\
\text { product of a system benchmark price and } \\
\text { the inverse of the system BCR; it can also } \\
\text { be expressed as } L C O E /(\text { value factor); } \\
\text { Less than or equal to benchmark price for } \\
\text { economic viability. }\end{array}$ \\
\hline
\end{tabular}

${ }^{a}$ Note that typical financial definitions of ROI normalize by investment cost only, rather than total cost, but we are restricting our scope for these metrics to combinations of total value and cost.

b The benchmark price can be arbitrarily chosen, although should be consistent across technologies for a meaningful comparison. Benchmark prices can vary by scenario and year. A variety of benchmark prices have been suggested in the literature, including an annual average marginal electricity price or prices from a norenewables system.

\footnotetext{
${ }^{39}$ Of course, relating different physical quantities (e.g., MW-to-MWh or tons-to-MWh) is also often done but could result in non-intuitive values. For example, the LCOE of a peaking unit can be numerically substantial due to the small number of hours that they operate. In another example, it is unclear how one would express LCOE, LVOE, NVOE, or other similar levelized per unit electrical energy quantity for certain assets that do not produce a net amount of electricity (e.g., flywheels).
} 
${ }^{c}$ Here, we are assuming that the system "benchmark price" is expressed in units of $\$ / M W h$. Profitability-
adjusted LCOE is the only system profitability metric that is not unitless.

The dimensionless system profitability metrics can be converted to measures with units that might be more readily compared with other measures. For example, multiplying system BCR by technology cost (e.g., LCOE) can suggest a technology cost target (matching LVOE and in units of dollars per megawatt-hour) that an R\&D program might want to achieve with the goal of reaching viability. Similarly, multiplying system ROI with LCOE would give a measure of NVOE. These relationships between the metrics are useful, but we caution that such simple relationships might hide some of the underlying differences between the metrics. For instance, in the example of measuring technology progress, reductions in LCOE or NVOE might suggest an improvement toward economic viability; however, in the general case - particularly when system value changes due to the technological innovation - these metrics can misconstrue the degree and even direction toward viability. We discuss this in more detail in Section 4.

System BCR, system ROI, system profit margin, and similar direct functions of system value divided by cost can be useful as direct measures of economic competitiveness. However, like all competitiveness metrics that include system value, it is difficult to consistently characterize technologies as one can with LCOE because system value of a technology is as much influenced by the system (via prices) as by the technology itself. Indeed, there is no way to completely divorce technology characteristics from the system and still appropriately characterize competitiveness. However, we can reduce the influence of changes in bulk system price, or "benchmark price," defined in Section 3.2, on system profitability, while maintaining the same ability to compare technologies. For this, we introduce a new system profitability metric, profitability-adjusted LCOE, ${ }^{40}$ which is equal to benchmark price divided by system BCR. Because benchmark price is a characteristic of the system and is consistent across technologies, profitability-adjusted LCOE is still able to evaluate competition between technologies as any other system profitability metric does. However, determining economic viability with profitability-adjusted LCOE requires understanding the benchmark price, whereas the other system profitability metrics reveals economic viability more directly without needing to define or assume a benchmark. Using the definition of "value factor" in Section 3.2 (LVOE divided by benchmark price), we can also express profitability-adjusted LCOE as LCOE divided by value factor. ${ }^{41}$ In this form, profitability-adjusted LCOE is based on two known measures in the literature (LCOE and value factor).

\section{Comparing Competitiveness Metrics}

In our view, the primary purposes of a competitive metric are to (1) convey whether a new asset is economically viable to a system planner; and (2) accurately compare different technology options, including their rank-order and their relative distances from viability. In this section,

\footnotetext{
${ }^{40}$ Another way to define profitability-adjusted LCOE is that it is the LCOE of an equally competitive "benchmark technology" (i.e., a technology with LVOE equal to benchmark price and equivalent system profitability to the technology in question). This definition could also apply to system LCOE, introduced in Section 3.4, but the associated metric of competitiveness would be NVOE rather than system profitability.

${ }^{41} 1$ /(value factor) can be seen as an "integration multiplier," similar to the concept of "integration costs" introduced in Section 3.4. For technologies that rely on non-energy services, the original and more-general definition for profitability-adjusted LCOE (benchmark price divided by system BCR) would be preferable to LCOE divided by value factor, as both LCOE and value factor approach infinite as reliance on energy value goes to zero.
} 
we compare the competitiveness metrics presented in Section 3 based on their ability to robustly serve these purposes. The comparisons will be made between the three groups of metrics as categorized in Table 2. The first group includes LCOE and LVOE, which are known metrics that do not comprehensively include both costs and value. The second group is composed of the existing and comprehensive metrics - NVOE, NVOC, and system LCOE - that are defined largely based on a net value per physical unit. The third group consists of the new system profitability metrics - system BCR, system ROI, system profit margin, and profitability-adjusted LCOE - that also comprehensive consider costs and system value by taking their ratios.

Metrics from the first group, LCOE and LVOE, fail to meet both purposes of a competitiveness metric presented above as they omit system value and technology costs, respectively. For example, a technology with a very high LCOE, such as a peaking generator that only operates sparingly during high price hours, may still be economically viable as long as its LVOE is also equally high. Given that the first purpose is not met, it is obvious that the second is not either. In fact, these shortcomings of LCOE in particular are what has motivated the development of the other competitiveness metrics in part in the first place.

Metrics from both the second and third groups all successfully meet the first purpose. Assets with zero or positive net value are in the money. ${ }^{42}$ These same assets would have a system BCR greater than (or equal to) one and positive (or zero) system ROI and profit margin. Beyond the binary question of whether an asset is economically viable, for those options that are not viable, a good competitiveness metric would provide information about the distance from viability. All the metrics from the second and third groups provide an indication of this distance. For example, a technology with an NVOE of $-\$ 10 /$ MWh can become economically viable if its LCOE is lowered by $\$ 10 / \mathrm{MWh}$ while keeping its LVOE identical.

At first glance, the different forms of net value, NVOE and NVOC, and, by extension, system LCOE are measures of profit similar to the system profitability metrics but just normalized by a physical unit of capacity or energy rather than dollars. NVOE, NVOC, and system LCOE give some sense of how far an unprofitable technology is from economic viability because we know that net value would be zero or greater if the technology were viable. But these metrics cannot be used to compare investments in different options because a unit of energy or capacity for one option has different economic value than a unit of energy or capacity from a different option. Likewise, these metrics cannot be used to measure improvement even in a single technology over time if the performance characteristics change through that improvement. In the general case a technological change would influence not just the cost for that technology but also the production profile or capability to provide other grid services - and thus system value - of that technology thereby can influence the directional change in system profitability.

We use a simple example to illustrate how the different metrics rank-order technologies differently from each other and, notably, how LCOE, NVOE, NVOC, and system LCOE rank the technologies differently than the system profitability ones. Our illustrative example is similar to the one presented by Joskow (2011), ${ }^{43}$ who presented it to show the insufficiency of LCOE compared to a metric that is similar to NVOC. We alter and extend this example to show the

\footnotetext{
${ }^{42}$ For system LCOE the benchmark for viability is when it is less than the benchmark price.

${ }^{43}$ We use the same system conditions as Joskow (2011) but alter the technology characteristics.
} 
advantages of the system profitability metrics. In this example, we assume a simplified electric power system with only two demand periods, peak and off-peak, and no other grid requirements. The peak demand period has 3,000 hours per year and an assumed electricity price of $\$ 90 / \mathrm{MWh}$, while the off-peak demand period has the remaining 5,760 hours per year and an assumed electricity price of $\$ 40 / \mathrm{MWh}$. In this toy system, we calculate our competitiveness metrics for five different technologies (Techs A-E), each with different assumed LCOEs and generation profiles during the two demand periods. Table 4 presents these assumptions and the resulting competitiveness metrics calculated based on the definitions provided in Section 3.

Table 4. Example Illustrating Differences Between Competitiveness Metrics

\begin{tabular}{|c|c|c|c|c|c|}
\hline \multicolumn{6}{|c|}{ Assumptions for a conceptual power system } \\
\hline \multicolumn{3}{|c|}{ Electricity Price in Off-Peak Period (\$/MWh) } & \multicolumn{3}{|c|}{40} \\
\hline \multicolumn{3}{|l|}{ Electricity Price in Peak Period (\$/MWh) } & \multicolumn{3}{|c|}{90} \\
\hline \multicolumn{3}{|l|}{ Number of Hours in Off-Peak Period (h) } & \multicolumn{3}{|c|}{5,760} \\
\hline \multicolumn{3}{|l|}{ Number of Hours in Peak Period (h) } & \multicolumn{3}{|c|}{3,000} \\
\hline \multicolumn{3}{|l|}{ Benchmark (Average) Price (\$/MWh) } & \multicolumn{3}{|c|}{57} \\
\hline & Tech A & Tech B & Tech C & Tech D & Tech E \\
\hline \multicolumn{6}{|c|}{ Technology assumptions } \\
\hline LCOE (\$/MWh) & 40 & 71 & 105 & 70 & 65 \\
\hline Capacity Factor during Off-Peak & 0.5 & 0.2 & 0.0 & 1.0 & 0.5 \\
\hline Capacity Factor during Peak & 0.1 & 1.0 & 1.0 & 1.0 & 0.0 \\
\hline \multicolumn{6}{|c|}{ Competitiveness metric calculations } \\
\hline LVOE (\$/MWh) & 44.7 & 76.1 & 90.0 & 57.1 & 40.0 \\
\hline NVOE (\$/MWh) & 4.7 & 5.1 & -15.0 & -12.9 & -25.0 \\
\hline NVOC (\$/kW-yr) & 15.0 & 21.3 & -45.0 & -112.8 & -72.0 \\
\hline System LCOE (\$/MWh) & 52.4 & 52.0 & 72.1 & 70.0 & 82.1 \\
\hline System BCR & 1.12 & 1.07 & 0.86 & 0.82 & 0.62 \\
\hline System ROI & 0.12 & 0.07 & -0.14 & -0.18 & -0.38 \\
\hline System Profit Margin & 0.11 & 0.07 & -0.17 & -0.23 & -0.63 \\
\hline Profitability-Adjusted LCOE (\$/MWh) & 51.1 & 53.3 & 66.6 & 70.0 & 92.8 \\
\hline \multicolumn{6}{|c|}{ Ranking based on the metrics (1 is most competitive) } \\
\hline LCOE & 1 & 4 & 5 & 3 & 2 \\
\hline LVOE & 4 & 2 & 1 & 3 & 5 \\
\hline NVOE & 2 & 1 & 4 & 3 & 5 \\
\hline NVOC & 2 & 1 & 3 & 5 & 4 \\
\hline System LCOE & 2 & 1 & 4 & 3 & 5 \\
\hline System BCR & 1 & 2 & 3 & 4 & 5 \\
\hline System ROI & 1 & 2 & 3 & 4 & 5 \\
\hline System Profit Margin & 1 & 2 & 3 & 4 & 5 \\
\hline Profitability-Adjusted LCOE & 1 & 2 & 3 & 4 & 5 \\
\hline
\end{tabular}


In this conceptual example, Techs $A$ and E generate electricity primarily during the off-peak (lower price) demand period. Tech B represents an intermediate load plant with generation occurring during both demand periods but weighted toward the (higher price) peak period. Tech $\mathrm{C}$ is a peaking plant and represents a highly dispatchable technology with high variable costs. Tech D operates at full capacity throughout the year akin to a baseload generator.

At the bottom of Table 4 is the rank-ordering of the technologies implied by the metrics. Based on these parameters and calculations, Techs A and B (in black) are economically viable - their system value is greater than their costs-whereas the opposite is true for the other technologies (Techs $\mathrm{C}-\mathrm{E}$ ), which are highlighted in red. The existing and non-comprehensive metrics (LCOE and LVOE) are unable to make this distinction as indicated by their suggested rank-ordering; these metrics position one of the viable Techs behind the non-viable ones. In contrast, all of the other metrics correctly delineate viable technologies from non-viable ones by correctly finding Techs A and B among the top two ranked technologies. This, of course, is by design. For example, a positive value for the net value metrics (NVOE and NVOC) indicates viability and, similarly, a value greater than one for system BCR suggests viability. ${ }^{44}$

However, when comparing within the group of profitable technologies (in black), or when comparing just the unprofitable technologies (in red), differences are apparent in the rankings between the metrics. For example, the rankings between NVOE and NVOC differ for the unprofitable technologies (Techs $\mathrm{C}-\mathrm{E}$ ) simply because the average capacity factors vary between these technologies; NVOE favors technologies with higher capacity factor compared to NVOC. Importantly, the rankings shown by NVOE, NVOC, and system LCOE also all differ with the ranking from the set of system profitability metrics, which we argue most accurately portray relative competitiveness between options by directly evaluating profitability. These differences in ranking occur for economically viable as well as non-viable technologies. We chose parameters for this conceptual example to highlight potential differences between metrics, but there are regions in parameter space where the metrics would agree. However, we argue that the system profitability metrics are more appropriate for conveying economic competitiveness in the general case. Of course, the metrics shown have other uses and advantages beyond competitiveness as we discuss elsewhere.

It is important to note that the technologies from the conceptual example in Table 4 can represent different technologies altogether, different configurations of the same basic technology (e.g., variations in hub height and rotor diameters of wind turbines, adding storage to PV plants) with different costs and generation profiles, or different vintages of the same technology over time. For example, Tech $\mathrm{C}$ and Tech $\mathrm{D}$ from the example in Table 4 could represent a single technology before and after a change, respectively. This change leads to a reduction in LCOE (by $\$ 35 / \mathrm{MWh}$ ) and a lesser reduction in LVOE (\$33/MWh) such that NVOE improves and apparently suggesting an overall technology improvement. However, system profitability actually decreases with this change (system BCR declines from 0.86 to 0.82 ) indicating that the "improved" technology is less economically efficient (i.e., an investment in the new technology returns less system value than an equivalent investment in the original one). More generally, a

\footnotetext{
${ }^{44}$ In this illustrative example, if electricity prices were the same in the two time periods, LCOE, NVOE (or system LCOE), and system profitability would all come to the same rank-ordering, because the value of a megawatt-hour would be consistent across the tech options. Other parameters could also result in aligned rank-orderings, but that would occur by happenstance and not an indication of robustness.
} 
technology could increase its NVOE or NVOC but, at the same time, decrease its system profitability, thus demonstrating the potential pitfall of using the existing competitiveness metrics to track technology progress.

What this means is that the limitations of NVOE, NVOC, and system LCOE apply to tracking technology progress over time as well as comparing two different technologies. In the former example of technology tracking, R\&D innovation could yield an increase in NVOE or NVOC, but system ROI might in fact decline, indicating that the technology might have moved farther away from economic viability. This example shows that NVOE, NVOC, and system LCOE have the potential to not only incorrectly rank-order technologies from the standpoint of profitability but also that the quantitative gap from viability measured by these metrics needs to be evaluated more carefully through system profitability measures. However, in the case where the expected economic value is approximately similar over time (e.g., production profiles remain static with technology innovation), changes in net value would closely approximate the degree of progress.

Note also that although the conceptual example includes only two demand periods (peak and offpeak) in an energy-only system, the differences between the metrics and the shortcomings of NVOC, NVOE, and system LCOE are not restricted to such systems. In principle, the two demand periods represent two separate grid requirements. System profitability can be applied to systems with any number of grid requirements and corresponding prices (e.g., 8,760 hourly prices, capacity prices, ancillary services) and the same advantages of system profitability demonstrated in this simple example would apply.

\section{Quantifying Competitiveness Metrics}

The prior sections present the conceptual basis behind competitiveness metrics and technology valuations. Robust quantifications of the metrics, including estimates of their costs and system value components, rely on detailed data and electric system models. Prior quantifications have used varied approaches, including relying on historical electricity market data to evaluate technology market value through a price-taker approach (e.g., Mills et al. 2018), production cost modeling to estimate operational value (e.g., Mehos et al. 2015), effective load carrying capacity calculations to estimate technology capacity credit (e.g., Madaeni et al. 2011), historical emissions and damage functions to estimate health and environmental value (e.g., Siler-Evans et al. 2013), and varied capacity expansion modeling approaches (e.g., Mills and Wiser 2012; Ueckerdt et al. 2013; Reichenberg et al. 2018; Hirth, Ueckerdt, and Edenhofer 2015; Heuberger et al. 2016; Heuberger et al. 2017; EIA 2018a). ${ }^{45}$

Many prior approaches are designed to assess technology system value for one or a small number of options only. Furthermore, certain approaches only tackle specific sources of system value (e.g., production cost models can be used to estimate the short-run operational value but inherently omit the longer-run resource adequacy value). Some approaches address value in physical terms but omit economic or monetary valuations. A truly comprehensive approach is not possible due to the diverse potential sources of cost and value from the diversity in grid services and technologies. An inherent tradeoff exists between comprehensiveness in scope versus fidelity. Nonetheless, among the approaches that focus on the most economically

45 This represents a sample of types of approaches and references only and is not intended to be comprehensive. 
significant grid services (energy and capacity) for bulk power generation technologies, CEMs provide a unique balance of these tradeoffs and can be an effective means to estimate technology competitiveness metrics. In this section, we describe how CEMs, particularly those based on optimization techniques, reveal sources and components of technology cost and system value, described in Section 2, and can be used to quantify competitiveness metrics introduced in Section 3. We also demonstrate an application using a specific CEM and note key caveats and limitations in such quantifications.

\subsection{Optimization-Based Capacity Expansion Models}

Optimization-based models apply basic economic supply-and-demand principles and, therefore, offer a framework to answer questions about technology competitiveness. In addition, the design and operation of electric power systems are often informed by optimization-based computer models that minimize costs while maintaining certain system attributes. For example, current electricity market auctions are cleared using optimization models that minimize total operating costs over a certain period, to commit and dispatch units in the most economical way subject to a suite of requirements (e.g., security-constrained unit commitment and economic dispatch). Utility planning software also often optimizes the build-out of new generation capacity by finding the portfolio with the overall lowest costs (including capital and operating costs) subject to load growth, retirement, and policy forecasts. Because optimization modeling plays such an integral role for power system planning and operations, it serves as a useful framework to conceptualize the sources of electric technology value (and costs).

Specifically, CEMs are uniquely well-suited to quantify technology competitiveness because their primary function is to find the most-desired portfolio of options given the various system needs and technology costs and attributes. Moreover, they serve this function by considering investment and dispatch decisions simultaneously, a valuable trait to evaluate both the short-run and long-run competitiveness of different options under diverse and changing environments. Modeling long run system needs and conditions is critically important for technology valuations given the sensitivity of prices and provisions to these factors. In an optimization-based CEM, the objective is to identify the least-cost portfolio given a set of constraints and technology parameters. ${ }^{46}$ As we describe below, they answer the three questions identified in Section 2 needed to evaluate cost and value: (1) How much of each service is provided by the different technology options? (2) How much is each unit of service worth to the system? (3) How much does it cost for each technology to provide the services?

Constraints in an optimization model directly represent grid requirements. For example, loadbalancing constraints reflect energy services, and reserve margin requirements establish capacity services. In addition to the set of constraints that specify grid requirements, CEMs model a suite of technology options that could provide the various services and satisfy the constraints modeled. Capacity and dispatch of the technology options are referred to as variables in a CEM. Associated with the variables are cost and performance parameters (e.g., capital, O\&M, heat rates, fuel costs, emission costs) that the optimization routine considers when identifying the least-cost solution. Importantly, these cost parameters influence technology costs and the price

\footnotetext{
${ }^{46}$ Appendix B describes how an optimization model arrives at the least-cost solution. It also suggests how the profitability concepts that we raise in the context of competitiveness metrics may be applicable to optimization solvers, which, to our knowledge, have not been found in the literature.
} 
of the grid service, where the price is the shadow price (also referred to as the dual price) of each constraint at the optimal solution. In other words, the service price is the marginal cost to provide the next increment of that service or the cost for the most-expensive option providing that service to meet the constraint. These marginal prices are natural outputs from the optimization model. ${ }^{47}$

The equilibrium prices and provisions can only be found by assessing the complex interactions between technology options and grid requirements. This feature is particularly important for accurate accounting as provision of grid services can be mutually exclusive resulting in opportunity cost considerations whereas others are not (e.g., a synchronous generator that provides energy also contributes to system inertia). Because of these interactions, one cannot simply sum multiple system value estimates derived from multiple models to arrive at a total system value. Conceptually, if all constraints are represented within a CEM then value components would be additive and the sum of all components would equal the total system value. Quantifying competitiveness metrics using CEMs would also ensure consistency between estimates for cost components and those for value components. For example, assuming a certain capacity factor to estimate technology cost and a different capacity factor to estimate system value would make them incomparable. By extracting cost and value components directly from the same scenario in a CEM would ensure these types of factors are consistent and help avoid accounting errors, such as double counting. Of course, all models have limitations and fidelity is a critical consideration for CEMs given their broad scope as we discuss in Section 5.3.

In summary, the equilibrium solution of an optimization-based model provides answer to the three questions raised above, which enables it to self-consistently estimate the constituent components (technology cost and system value) of competitiveness metrics. In fact, in equilibrium, the total costs for each option that is chosen matches the total system value provided by that option given the service provisions and marginal prices. ${ }^{48}$ Furthermore and potentially of greater utility, optimization-based CEMs can also be used in assessments of options that are not chosen in the preferred mix by using the equilibrium prices, as we demonstrate next.

\subsection{Demonstration of Competitiveness Metrics Quantification}

The modeling exercise presented in this section is designed to demonstrate how technology costs, system value, and competitiveness metrics can be quantified using a CEM designed to represent a realistic system. This exercise also highlights how the different metrics appropriately (or in certain circumstances, incorrectly) compare technologies. Although we present numerical values to support our discussion and conclusions, this analysis is not intended to provide definitive quantitative estimates of technology competitiveness or value. Instead, the modeling analysis is used only to illustrate potential applications for the metrics and how the metrics themselves compare. While we present an implementation to calculate the metrics using a

\footnotetext{
${ }^{47}$ For capacity expansion models, the marginal cost, in the general case, includes both fixed (capital) costs as well as operating costs. In contrast, the energy components in current restructured markets are based on operating costs only. Another relevant measure that is a natural outcome of CEMs is the reduced cost for each decision variable in the model, which is similar to the "net cost" or "net value" metrics we presented in Section 3.

${ }^{48}$ Cochran et al. (2015) introduced a concept of "economic carrying capacity" to refer to the amount of renewable energy on a system where the renewable energy's value exceeds or equals its cost. In fact, this concept can be applied to any technology and is implicitly occurring in any condition where economic equilibrium is reached. Note that profits (inframarginal rent) are also possible in CEM models, resulting in system value that may be higher than cost.
} 
specific CEM, the Regional Energy Deployment System (ReEDS) model (Eurek et al. 2016), our CEM-based method to generate competitiveness metrics is generalizable to other optimizationbased CEMs. In Section 5.3 we discuss key uncertainties and limitations of the metrics and their quantifications through modeling.

To show example calculations of technology-specific costs, values, and competitiveness, we use ReEDS, ${ }^{49}$ a capacity expansion and dispatch model of the contiguous United States electricity sector that uses a linear program (LP) to find the cost-optimal capacity and generation portfolio through 2050. The primary spatial representation in ReEDS includes 134 distinct "balancing areas" (BA), and its temporal resolution includes 17 time-slices for each year. Constraints are applied to ensure electricity demand and supply (including imports and exports) are balanced during each of the time-slices, which represent different seasonal/diurnal periods. Other electric sector requirements, such as planning reserve margin (capacity), and multiple different operating reserves (ancillary services) requirements must be satisfied in each BA and time period.

To meet the electricity sector requirements, ReEDS chooses from a broad array of the major electricity generation technologies, storage technologies, and transmission infrastructure.

Additional spatial detail is given to wind and solar generators via more regional options and grid connection supply curves. In addition, to better represent the unique characteristics of VREs, ReEDS performs a statistical estimation of the marginal curtailment rates and uses 8,760 hourly data to estimate marginal capacity credit for potential new VRE options. ReEDS also includes additional operating reserve regulation and flexibility requirements for VREs (Cole et al. 2018).

ReEDS is a sequential optimization model that solves every two years until 2050, updating parameters between every solve period. For each solve period, the optimization routine finds the solution with the lowest present value cost of meeting the electric sector requirements, assuming equivalent operation of the system for a 20 -year evaluation window. ${ }^{50}$ From each ReEDS solve year, marginal costs (prices) are extracted for each of the various requirements, and combining these prices with estimated technology provisions for each requirement allows us to calculate value components for each option during that solve. ${ }^{51}$ Cost and value components can be extracted for all technology options, not just for technologies that were chosen in the model solution. ${ }^{52}$ Finally, combining cost components with value components allows us to calculate competitiveness metrics.

\subsubsection{Example Service Prices From ReEDS}

In each solve, ReEDS implicitly considers the cost, value, and competitiveness of tens of thousands of technology options across all the model regions. Value components for each

\footnotetext{
${ }^{49}$ Specifically, we use the 2018 final release version of ReEDS used in and the Mid-case assumptions from Cole et al. (2018).

${ }^{50}$ Formulations with different representations of foresight, including intertemporally optimized models, would have different outcomes, as we discuss in Section 5.3.

${ }^{51}$ As ReEDS is a LP, marginals on constraints are a standard output of a solve. The provisions are also a direct output of ReEDS based on the "level" value of the variables.

${ }^{52}$ Value components for potential dispatchable technologies that are not chosen are more difficult to extract because the optimal generation profile is not known. We overcome this by perturbing the solution by prescribing a small amount of investment (in dollar terms) in the dispatchable technology and allow the model to build and operate the plant based on this set dollar investment.
} 
technology option are determined by those technologies' service provisions and the local prices for energy, capacity, and ancillary services. These prices are endogenously estimated in the model and, therefore, vary by scenario modeled. Figure 1 shows national and annual average prices for energy, capacity, and the three operating reserve services modeled in ReEDS for two example scenarios - one that is similar to the Mid-case from Cole et al. (2018) and an example high solar scenario where $41 \%$ of 2040 generation is from PV. Here, we do not focus on the numerical values of these prices but only highlight that these prices can vary between scenarios and grid services - thereby affecting the sources and magnitudes of value for different technologies. Furthermore, while Figure 1 shows the average prices for the contiguous United States as a whole, prices can vary between regions and time-slices. Figure 2 shows energy prices during select time periods for two sample regions, one in Iowa and another in California.

Regional prices are affected by transmission, including transmission losses, capacity from the existing transmission network, and the cost of any new transmission expansion. Because system value is influenced by the prices, transmission-related effects are implicitly captured in system value estimates. More generally, variations in prices throughout the year, across years, and between regions can affect the system value of different technologies depending on their location and production profiles.
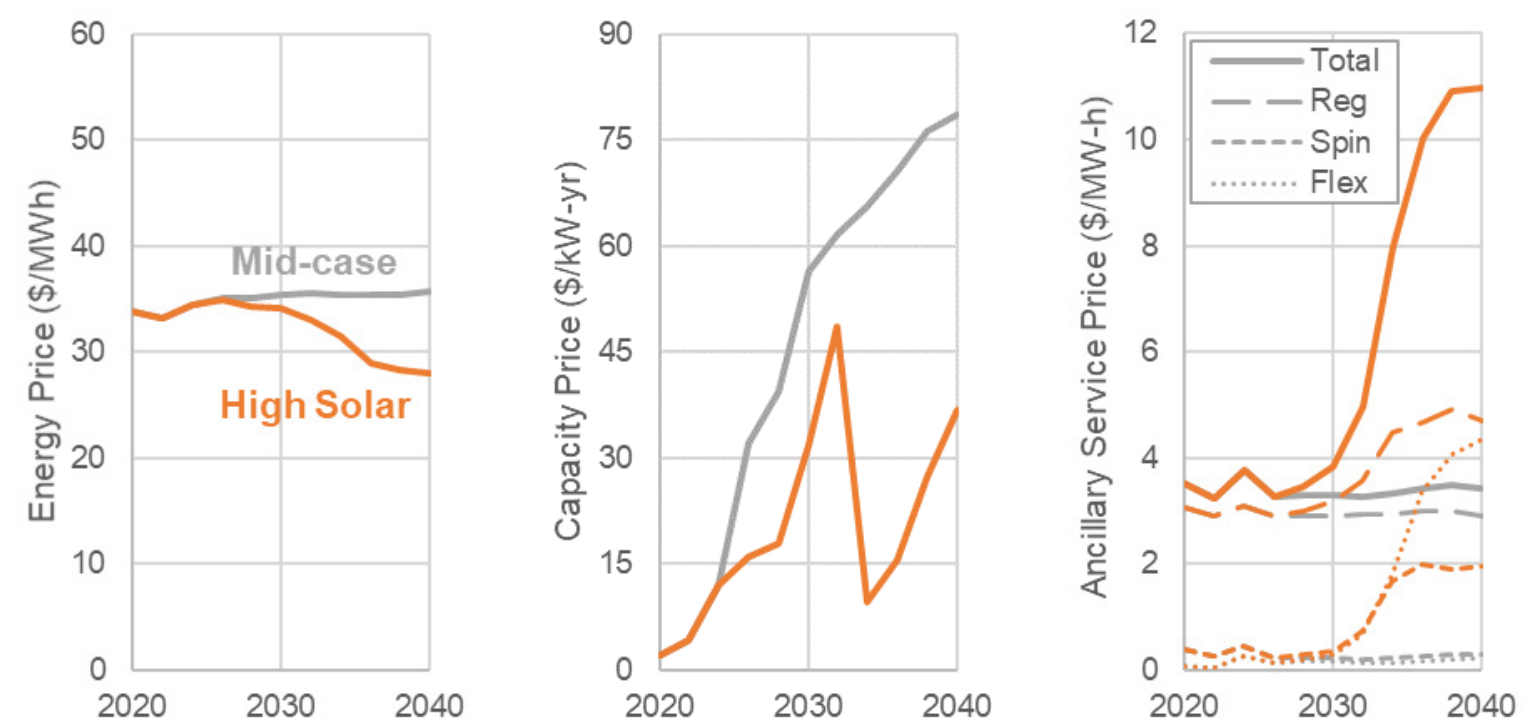

Figure 1. Annual average (left) energy, (middle) capacity, and (right) ancillary service prices from two illustrative scenarios

ReEDS includes three operating reserve types: $\operatorname{Reg}=$ regulating reserves, Spin = Contingency spinning reserves, and Flex $=$ flexibility reserves (see Cole et al. 2018). The High Solar scenario reaches $41 \%$ utility PV penetration by 2040. Numerical values are illustrative only and not definitive estimates. 
lowa

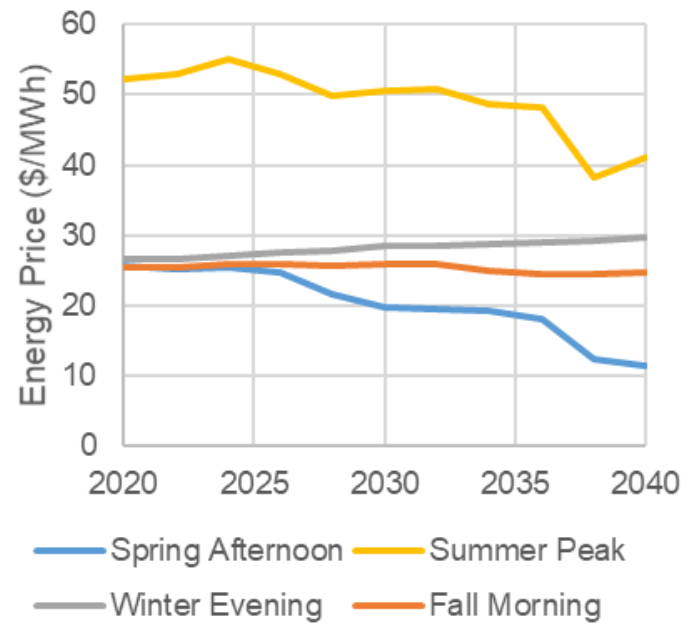

California

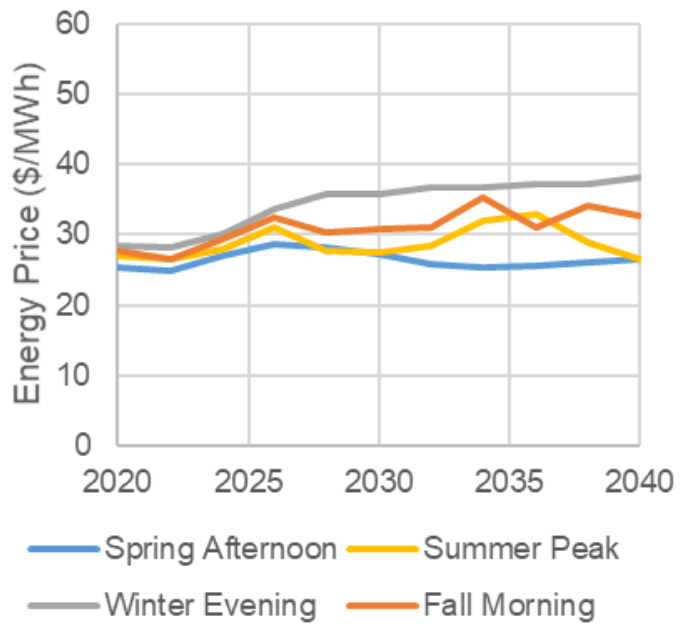

Figure 2. Modeled energy prices by select time-slices in two sample model regions in lowa (left) and California (right)

Numerical values are illustrative only and not definitive estimates.

\subsubsection{Examples of Onshore Wind Resource Curves}

Combining value components with costs allows us to calculate the full suite of competitiveness metrics presented in Section 3 for every technology option available to the model. Technology options in ReEDS include different technology types (e.g., wind versus PV) as well as different sites and resource classes for a single technology. For example, ReEDS uses 17,800 unique variables to represent the onshore wind resource in the contiguous United States, and the costs, value, and competitiveness metrics can be calculated for each of these variables. ${ }^{53}$ Figure 3 shows estimates for three groups metrics-LCOE and LVOE (top), NVOE and NVOC (middle), and system ROI (bottom) - for the full onshore wind resource represented in ReEDS based on in an illustrative scenario in 2030. These estimates are specific to the cost assumptions, endogenous prices, and service provisions modeled in this scenario.

This capability enables a different view of the wind resource supply beyond the traditional LCOE supply curve by not only accounting for regionally varying costs and performance but also the variations in system needs, prices, and capacity mix. For example, in the scenario shown in Figure 3, there are about $110 \mathrm{GW}$ of wind resource in the contiguous United States that is within $10 \%$ of system profitability and $560 \mathrm{GW}$ within $20 \%$ (see bottom panel). ${ }^{54}$ One possible application is to provide a fuller picture of the competitiveness of wind technologies (or any other technology) under a range of future market, technology, or policy scenarios. Often, traditional scenario modeling using CEMs provides estimates of future deployment given a set of assumptions, such as future technology cost and performance improvements. Sensitivity analysis can be used to assess deployment ranges under a wide range of assumptions, but there remains a

\footnotetext{
${ }^{53}$ There are 356 wind resource regions, 10 techno-resource groups, and 5 supply curve steps that represent spur line connections for wind. Each of these options can have different costs and performance characteristics (annual capacity factor as well as production profiles).

${ }^{54}$ See Cole et al. (2018) for the underlying assumptions used for these illustrative modeling scenarios.
} 
one-to-one mapping of deployment results with a set of assumptions (e.g., a set of assumptions gives a certain single-value estimate for the amount of capacity installed). This traditional application does not provide much information about how close the remaining resource might be from profitability. The new capability demonstrated here enables evaluations of the full set of options - those that are chosen and those that are not—which can be particularly useful when knife-edge solutions are common. However, as with LCOE supply curves caution is warranted that resource curves showing system profitability (or other competitiveness) metrics do not reveal the quantity to deploy as they are all based on marginal prices. In other words, these curves provide a static characterization of the resource and do not directly reflect economic or market potential. 

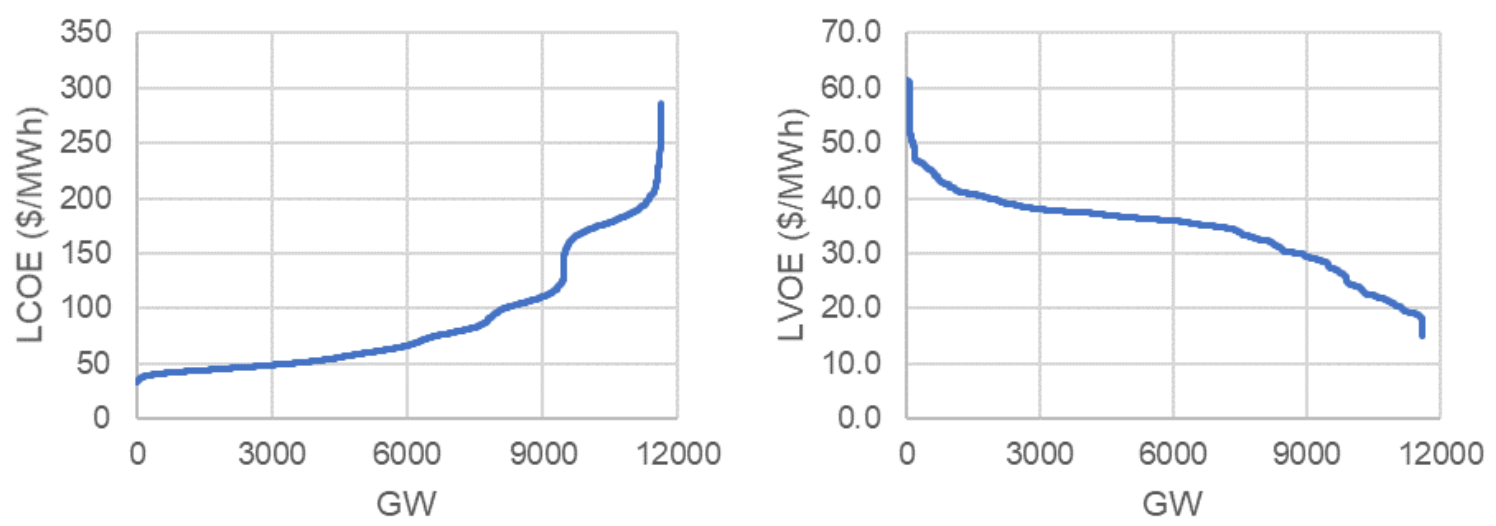

(top) LCOE and LVOE
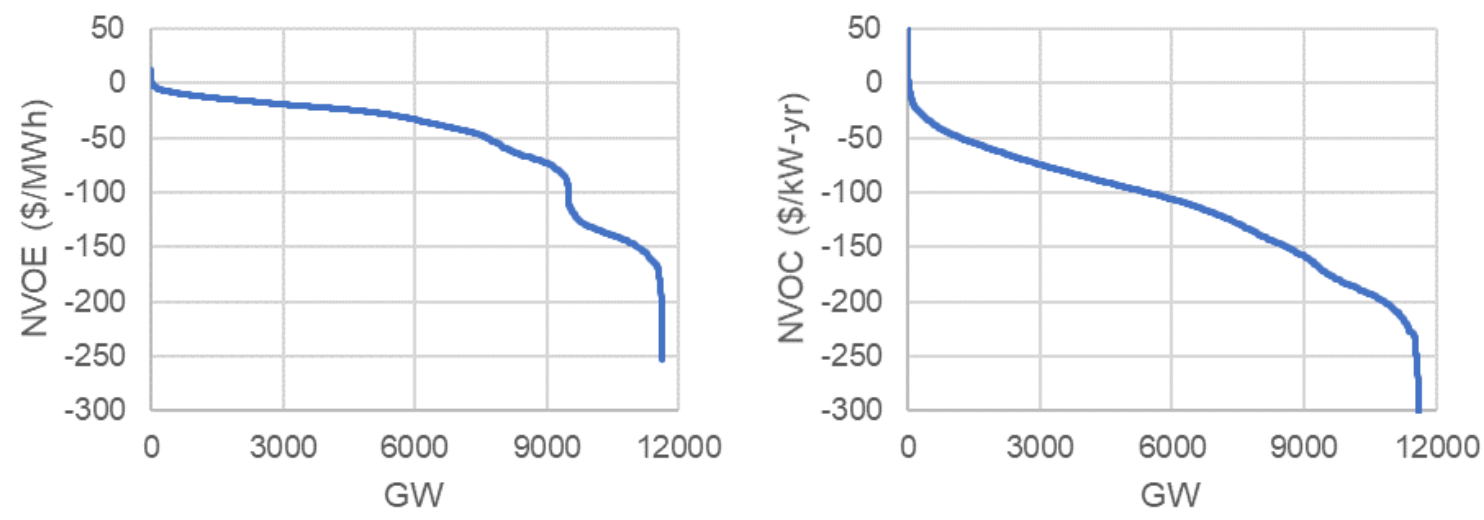

(middle) NVOE and NVOC
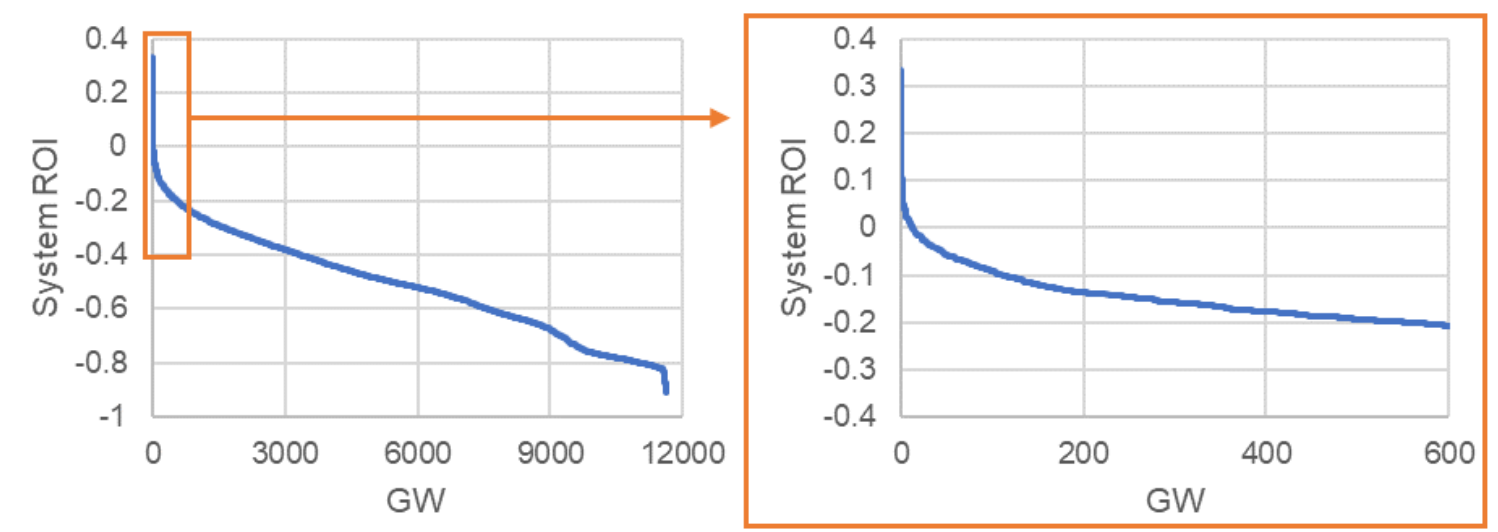

(bottom) System ROI

Figure 3. Competitiveness metric wind resource curves in $\mathbf{2 0 3 0}$ from an illustrative scenario

Resource curves reflect the full contiguous U.S. onshore wind resource in 2030. For each metric, the wind resource is ranked from the "best" site to the worst according to the metric. Vertical axes are different across panels. Numerical values are illustrative only and not definitive estimates. 
Figure 4 shows similar resource curves for system LCOE and profitability-adjusted LCOE, and it compares them with the traditional LCOE supply curve. Given that these three metrics are in the same common units, they can be compared on the same figure but the choice of the benchmark price used for system LCOE and profitability-adjusted LCOE can significantly impact the interpretation of the metrics. Here, the same benchmark price is used for system LCOE and profitability-adjusted LCOE and the benchmark price reflects the LVOE of a hypothetical "flat block" technology that operates at 100\% capacity factor through the year and receives full capacity credit. ${ }^{55}$ For this illustrative scenario and year, the benchmark price was found to be \$42/MWh. Figure 4 shows how, for this choice of benchmark price, system LCOE and profitability-adjusted LCOE are consistently higher than LCOE for nearly all wind resource sites, which means the system value of wind is generally lower than the system value of the hypothetical "flat block" technology. Potential reasons for this are that the wind production profiles are often not well-correlated with electricity demand, and that the wind resources can be far from high demand centers. Differences between system LCOE and profitability-adjusted LCOE are evident from Figure 4; however, this is not a general result for all conditions and technologies.

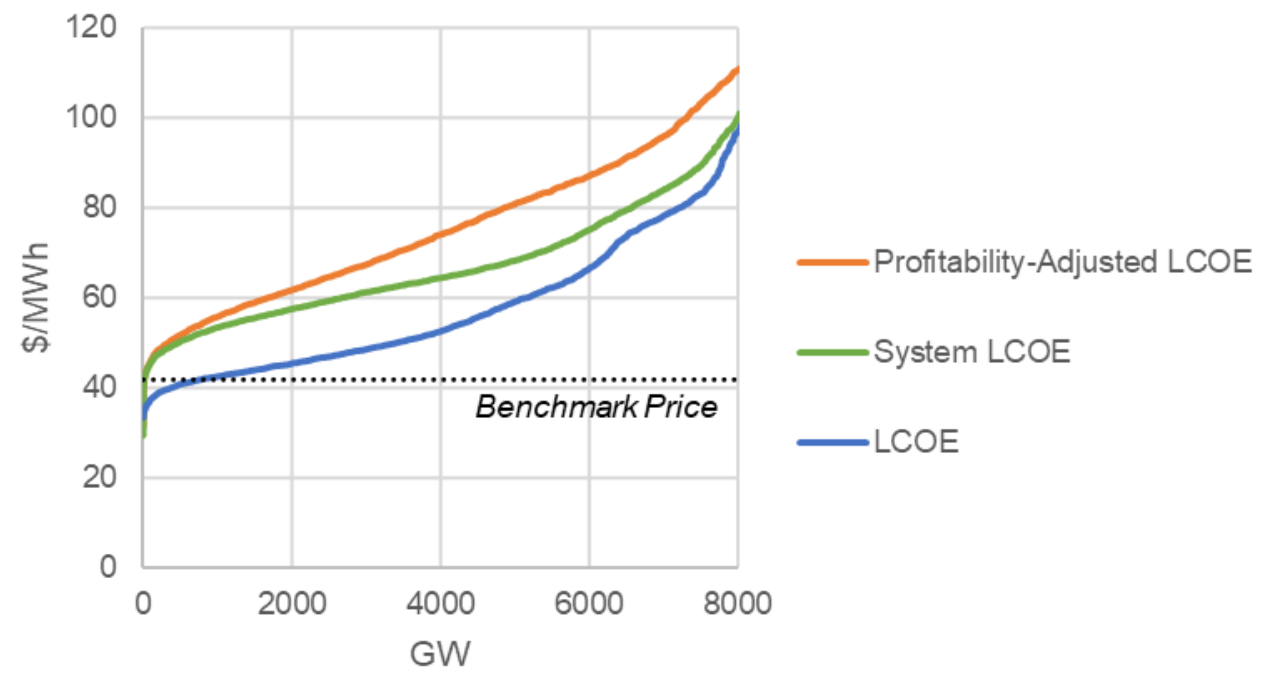

\section{Figure 4. LCOE, system LCOE, and profitability-adjusted LCOE onshore wind resource curves in 2030 from an illustrative scenario}

The resource is cut off at $8,000 \mathrm{GW}$ in this figure. The benchmark price reflects the LVOE of a hypothetical "flat block", and the same benchmark price is used to calculate both system LCOE and profitability-adjusted LCOE. Numerical values are illustrative only and not definitive estimates.

\footnotetext{
55 The energy component of the benchmark price is equivalent to time-averaged electricity price. Our definition of benchmark price also conceptually assumes the flat-block is distributed across the United States weighted by energy and capacity requirements. A benchmark price could account for all services; however, the benchmark price used here only includes energy and capacity prices and excludes ancillary service prices.
} 


\subsubsection{Examples of Cross-Technology Comparisons}

In addition to assessing the competitiveness between different regional and resource class options for a single specific technology, competitiveness metrics can also be used to compare across technologies. In order to evaluate technologies that are chosen and those that are not in the equilibrium solution, we apply a method in which we perturb the optimal solution by prescribing a small minimum dollar investment in each set of generation technologies but allow the model to choose the distribution of that investment between capital and operating costs and at the mostpreferred location. ${ }^{56}$ Figures 5-7 show example results from such a test, where we prescribe a $\$ 1$ million investment in each of the seven technology types shown in the 2030 solve year for an illustrative scenario.

Figure 5 shows estimated LCOE and LVOE, by component, for the seven technologies. For LCOE, it shows overall differences and reveals relatively capital- or fuel-intensiveness. Figure 5 also shows total LVOE differences and the distributions across value streams. Across all of the technologies shown, the primary value streams are energy and capacity in large part because the depth of those markets are much greater than the ancillary service requirements in these scenarios ${ }^{57}$ Because the two metrics shown in Figure 5 are ones that are levelized by electrical energy, they poorly reflect the economics for those where the primary grid services provided do not include energy. For example, natural gas combustion turbines (NG-CTs), plants that are typically used for peaking needs, are shown to have an LCOE (and an LVOE) that extends beyond the chart whereas new NG-CT capacity is one of the common deployment choices made by the model. This demonstrates how these two metrics fail to convey the economic competitiveness between a diverse set of technologies that provide a broad range of grid services.

\footnotetext{
${ }^{56}$ One could also prescribe a specific megawatt-hour or megawatt of a technology; however, that would bias the solution toward specific grid services. Instead, prescribing a fixed dollar amount is neutral to any individual service and would target the set of grid service provisions that would offer the most overall system value.

${ }^{57}$ For example, we assume spinning reserve requirements to be $3 \%$ of demand in each time-slice.
} 


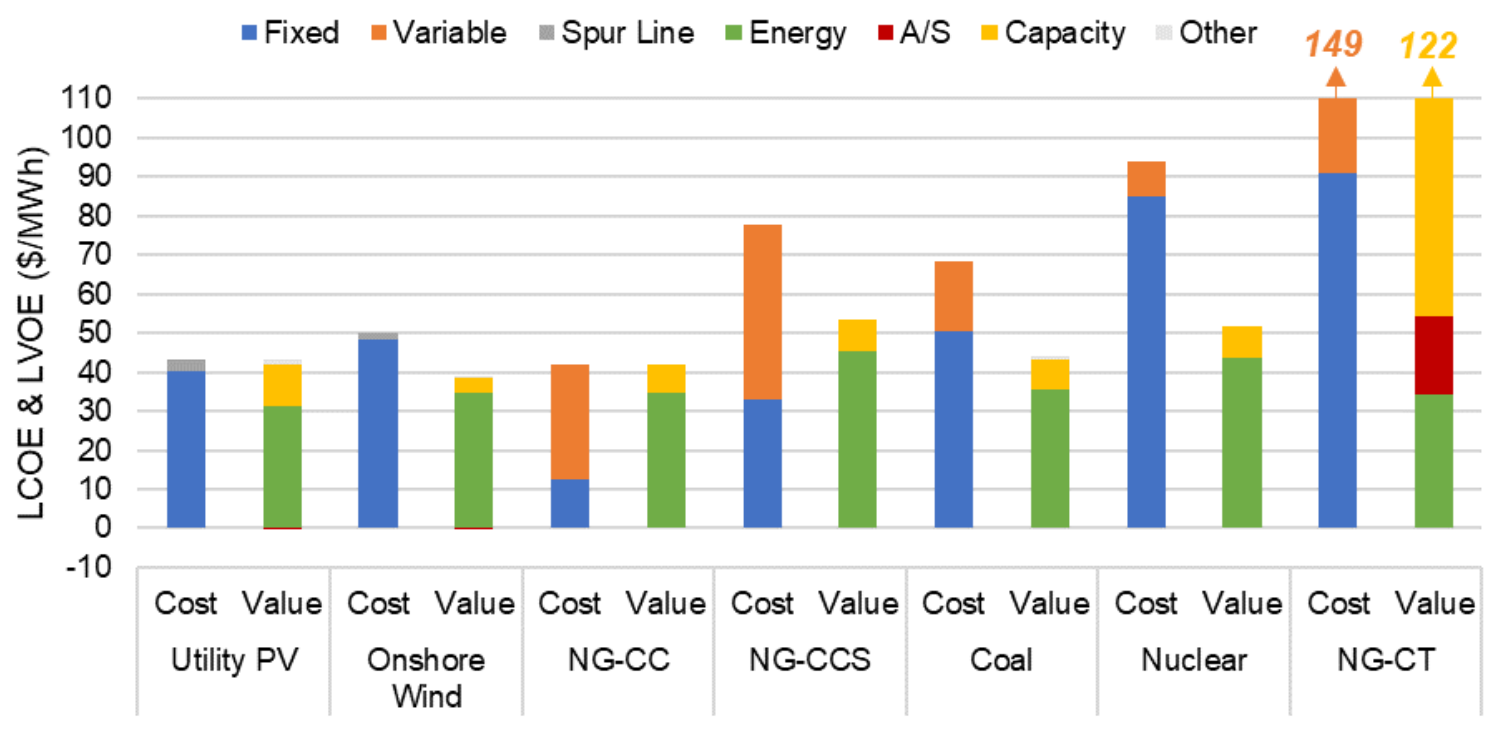

Figure 5. 2030 LCOE and LVOE estimates by component from an illustrative scenario

$\mathrm{A} / \mathrm{S}=$ ancillary services; NG-CC = natural gas combined cycle; NG-CCS = natural gas combined cycle with carbon capture and sequestration; NG-CT = natural gas combustion turbine. "Other" category includes values from all model constraints besides energy, capacity, and ancillary services ones. Estimates for PV include the effects of the permanent $10 \%$ federal investment tax credit. Numerical values are illustrative only and not definitive estimates.

Comparing the total LCOE and LVOE in Figure 5 reveals overall differences in viability between technologies. The total LCOE and LVOE are similar in magnitude for certain technologies (utility PV, wind, NG-CC, and NG-CT), meaning that they are either economically viable or are close to being economically viable. However, for other technologies (NG-CCS, coal, and nuclear) LVOE is noticeably lower than LCOE, signaling a considerable gap to viability. This is consistent with the deployment results for this scenario, where utility PV and NG-CC are the predominant technologies deployed in 2030 for this particular set of conditions (see the Mid-case from Cole et al. 2018).

Figure 6 shows this relative technology competitiveness more directly through a subset of competitiveness metrics. All three metrics shown in Figure 6 identify utility PV and NG-CC as viable (e.g., NVOE, NVOC, and system ROI are all zero or slightly positive), which is consistent with the deployment outcomes; however, they differ in suggesting the viability of some of the other technologies. Most notably, significant disagreement exists between the suggested competitiveness of NG-CT technologies: NVOE would suggest that NG-CT, NG-CCS, and nuclear possess the same extent of non-viability whereas NVOC and system ROI suggest that NG-CT and onshore wind are noticeable closer to viability than the other technologies. This example highlights how NVOE does not properly compare technologies that provide a wide range of grid services beyond energy. In fact, NVOC has a similar shortcoming but happens to be aligned with the system profitability metrics in this example. In contrast, system ROI and the other system profitability metrics do not have any intrinsic bias toward any specific grid service. 

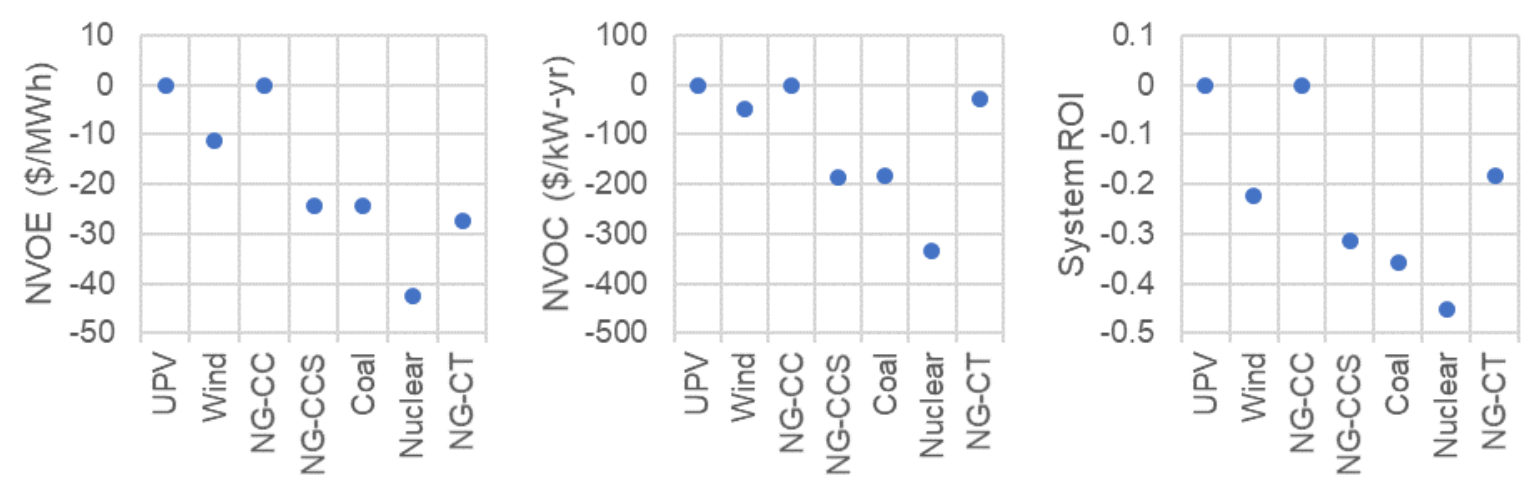

Figure 6. Cross-technology comparison of 2030 NVOE (left), NVOC (middle), and system ROI (right) from an illustrative scenario

UPV = utility PV; NG-CC = natural gas combined cycle; NG-CCS = natural gas combined cycle with carbon capture and sequestration; NG-CT = natural gas combustion turbine. Numerical values are illustrative only and not definitive estimates.

Figure 7 shows the estimated 2030 LCOE, system LCOE, and profitability-adjusted LCOE (a system profitability metric) for the same set of generation options and illustrative scenarios. We use the same benchmark price as in Figure 4 for both system LCOE and profitability-adjusted LCOE. LCOEs for utility PV, NG-CC, and onshore wind options are the lowest while the LCOE for NG-CT is greater than the maximum value on the chart because ReEDS relies on NG-CT primarily as a capacity resource with little utilization for energy. The system LCOE metric shows a similar behavior, and the illustrative results shown in the figure are qualitatively consistent with those found in the literature: PV (at low penetrations) and the dispatchable technologies have production profiles that are generally better-correlated with demand (and therefore energy prices) compared with onshore wind; therefore, their system LCOE is lower than their traditional LCOE whereas onshore wind's system LCOE is slightly higher than its LCOE. However, system LCOE is still unable to reflect the economics of non-energy resources, such as NG-CTs in our scenario, robustly as the system LCOE of NG-CT is higher than that of the other technologies that do not experience deployment in the scenario. This is in contrast to profitability-adjusted LCOE, which shows NG-CT more aligned with the other technologies that achieve deployment by more directly comparing the economic value of technologies that provide different grid services. 


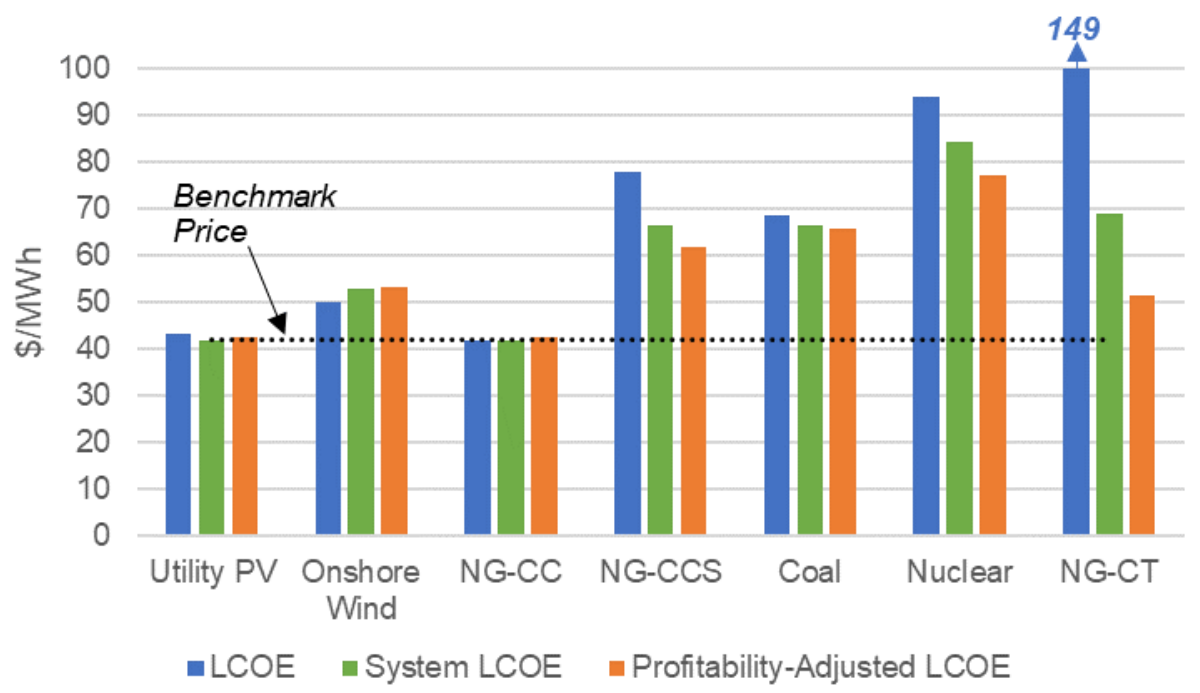

Figure 7. Cross-technology comparison of 2030 LCOE, system LCOE, and profitability-adjusted LCOE from an illustrative scenario

NG-CC = natural gas combined cycle; NG-CCS = natural gas combined cycle with carbon capture and sequestration; NG-CT = natural gas combustion turbine. The benchmark price shown here reflects the LVOE of a hypothetical "flat block", and the same benchmark price is used to calculate both system LCOE and profitability-adjusted LCOE and for all technologies. Estimates for PV include the effects of the permanent $10 \%$ federal investment tax credit. Numerical values are illustrative only and not definitive estimates.

\subsubsection{Example of Exploration of Increasing VRE Penetration}

Quantifying the competitiveness metrics using a CEM such as ReEDS can enable research of the economics of VRE integration, which is one of the original motivations for the development of many of the known metrics (e.g., system LCOE). Figure 8 shows value factor as a function of penetration for onshore wind and PV using scenarios where we force increasing investments in these technologies over time. ${ }^{58}$ As described in Section 3.2, a technology's value factor is its LVOE divided by a benchmark price. The benchmark price used here to calculate value factor is also based on the system value of a "flat-block" as before; however, it is important to note that this benchmark price changes over time and is scenario-dependent (see Figure 9).

\footnotetext{
${ }^{58}$ For these scenarios, prescribed investments start in 2026 and increase annually through 2040 . Other implementations, such as prescribing generation shares or capacity deployment are also possible and commonly done. The wind and PV technologies represented in ReEDS largely represent advancements to current technologies and do not include possible configuration changes (e.g., hybrid PV and storage plants). Different technology configurations should be evaluated separately and could yield quantitatively and qualitatively different value factor and competitiveness metric trends than those shown here.
} 
The trends from Figure 8 are qualitatively consistent with the literature (Wiser et al. 2017), where VRE value factor declines with penetration due primarily to the correlation in output profiles between different VRE sites. ${ }^{59}$ In addition to the value factor declines for both wind and $\mathrm{PV}$, Figure 8 shows how the value factor for PV is typically greater than that of wind at low penetrations but drops more precipitously at high penetrations. This trend is also consistent with those found in the literature. However, the slope of the decline can be sensitive to the degree of geographic diversity and the degree of system flexibility (Mills and Wiser 2014).

Profitability-adjusted LCOE can be expressed as LCOE divided by value factor and one can examine how the competitiveness changes with penetration. ${ }^{60}$ For example, a technology with a value factor of 0.5 would result in a profitability-adjusted LCOE that is two times greater than LCOE. This relationship represents an economic system value relationship similar to and a generalization of the previously-recognized relationship between curtailment and LCOE (Denholm and Margolis 2007), where curtailment and LCOE are related because curtailment reduces the amount of electrical energy production (i.e., the denominator in LCOE). Profitability-adjusted LCOE is similarly related to value factor, but the relationship comes from the reduced economic value reflected in value factor rather than physical production (MWh) reductions. ${ }^{61}$

Figure 9 shows LCOE and profitability-adjusted LCOE over time for the same increasing wind and PV scenarios shown in Figure 8. The LCOEs shown in Figure 9 for both wind and PV are relatively flat and even slightly increasing over time due to a combination of changing tax incentives and increasing selection of lower-quality sites, which counteract the cost and performance improvements assumed in these scenarios. In fact, the increasing LCOE trends shown in Figure 9 reveal that LCOE is an imperfect metric as part of the reason sites with higher LCOE might be chosen is because they offer greater system value. The increase in profitabilityadjusted LCOE is significantly higher than changes in LCOE and directly corresponds to the decline in value factor shown in Figure 8. For example, in 2040 where a wind penetration of about $50 \%$ occurs, the value factor is slightly greater than $50 \%$, leading to a profitability-adjusted LCOE that is slightly less than two times greater than the LCOE $(\$ 110 / \mathrm{MWh}$ versus $\$ 60 / \mathrm{MWh})$ in the same year.

\footnotetext{
59 This results in both declining energy value and capacity value. Other reasons for declining value factor are the potential increases in operating reserve requirements with VRE deployment and increasing grid connection costs when lower-cost sites are depleted.

${ }^{60}$ See Section 3.5.

${ }^{61}$ Of course, reducing electricity production also typically results in reductions in economic value (if prices do not increase significantly), but changes to profitability-adjusted LCOE reflect both changes in electricity production (i.e., curtailments) as well as changes in the magnitude and profile of energy prices.
} 


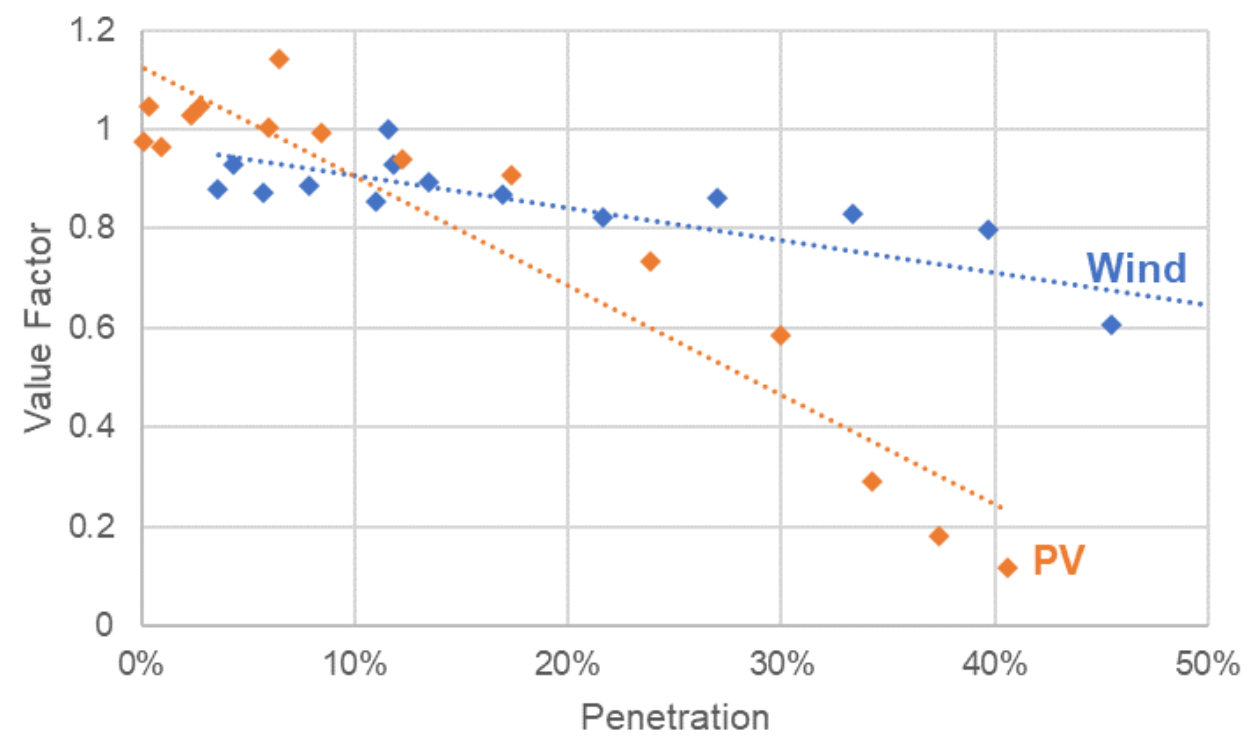

Figure 8. Value factor for onshore wind and utility PV as a function of penetration

The benchmark price used for the value factor calculation reflects the LVOE of a hypothetical "flat block. Linear trendlines are used to illustrate general trends only. Numerical values are illustrative only and not definitive estimates.
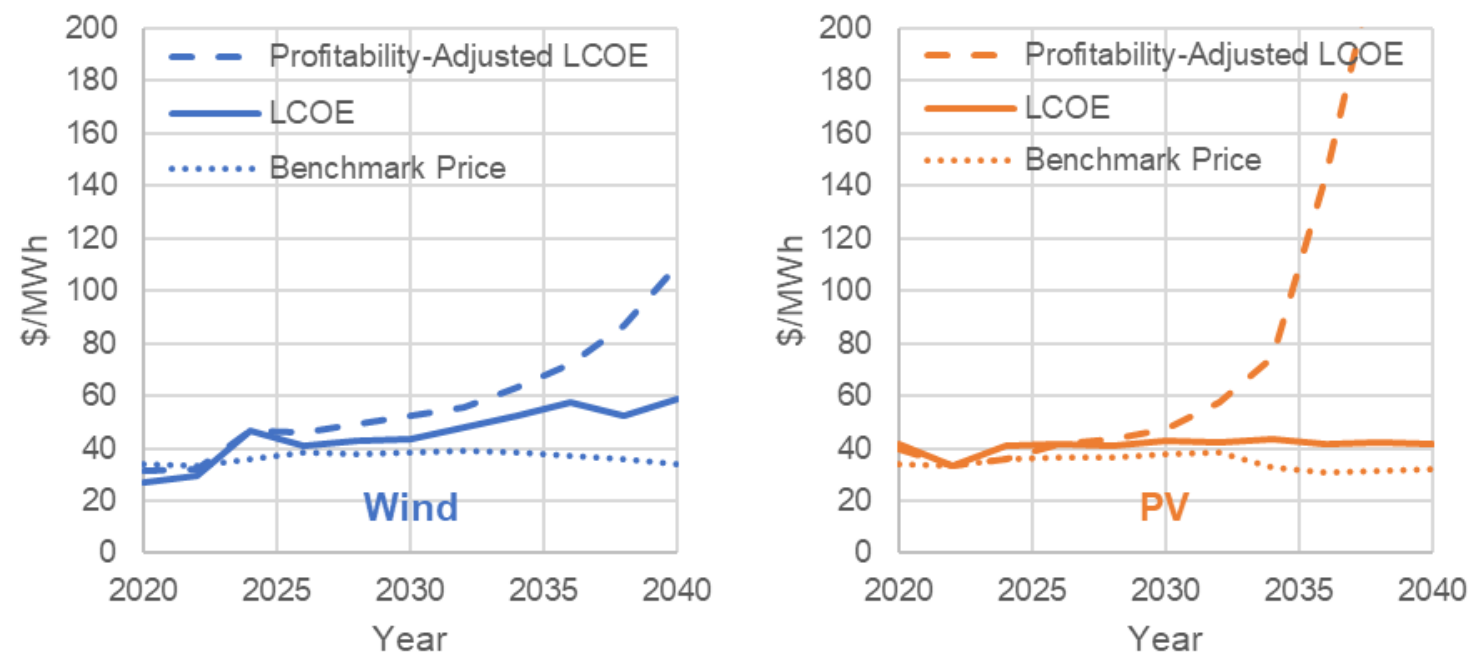

Figure 9. LCOE and profitability-adjusted LCOE for wind (left) and utility PV (right) over time and with increasing penetration

Benchmark prices, based on the LVOE of a "flat block," vary over time and across scenarios. The wind scenario reaches $51 \%$ penetration by 2040 and the PV scenario reaches $41 \%$ penetration by 2040 . Numerical values are illustrative only and not definitive estimates. 
Figure 10 shows the system ROI for the same increasing VRE scenarios. In addition to the total system ROI measures indicated by the black lines, which show the same behavior as in the previous figures, the stacked area charts in Figure 10 show the cost and value components of system ROI and how they change over time. Negative bars show the cost (and negative value) components, which are dominated by capital costs for wind and PV, but one can also observe that the shares of total costs from spur lines and ancillary services ${ }^{62}$ increase over time (and with increasing penetration in these scenarios). Among the value components (positive areas in Figure 10), we show how the sources of system value - energy and capacity services - generally decline with penetration. The decline in energy value is due to the decrease in energy prices, particularly during times of high VRE production, as well as the increase in curtailment with higher VRE shares. The decline in capacity value is also due to the extent of correlation between VRE production and demand. The marginal capacity credit of PV, in particular, can approach zero at sufficiently high penetrations as the net peak demand moves to the late evening hours. ${ }^{63}$

The increasing VRE examples are selected as they are similar to prior analyses of system value and for other competitiveness metrics (e.g., Mills and Wiser 2012; Ueckerdt et al. 2013; Hirth et al. 2015; Lamont 2008). However, a similar analysis can be performed to analyze the impacts of increasing penetration of other technologies, including baseload and dispatchable ones. In fact, the system profitability metrics are, in concept, applicable to any electric system asset including those whose primary functions do not include electricity production, for example transmission infrastructure investments.
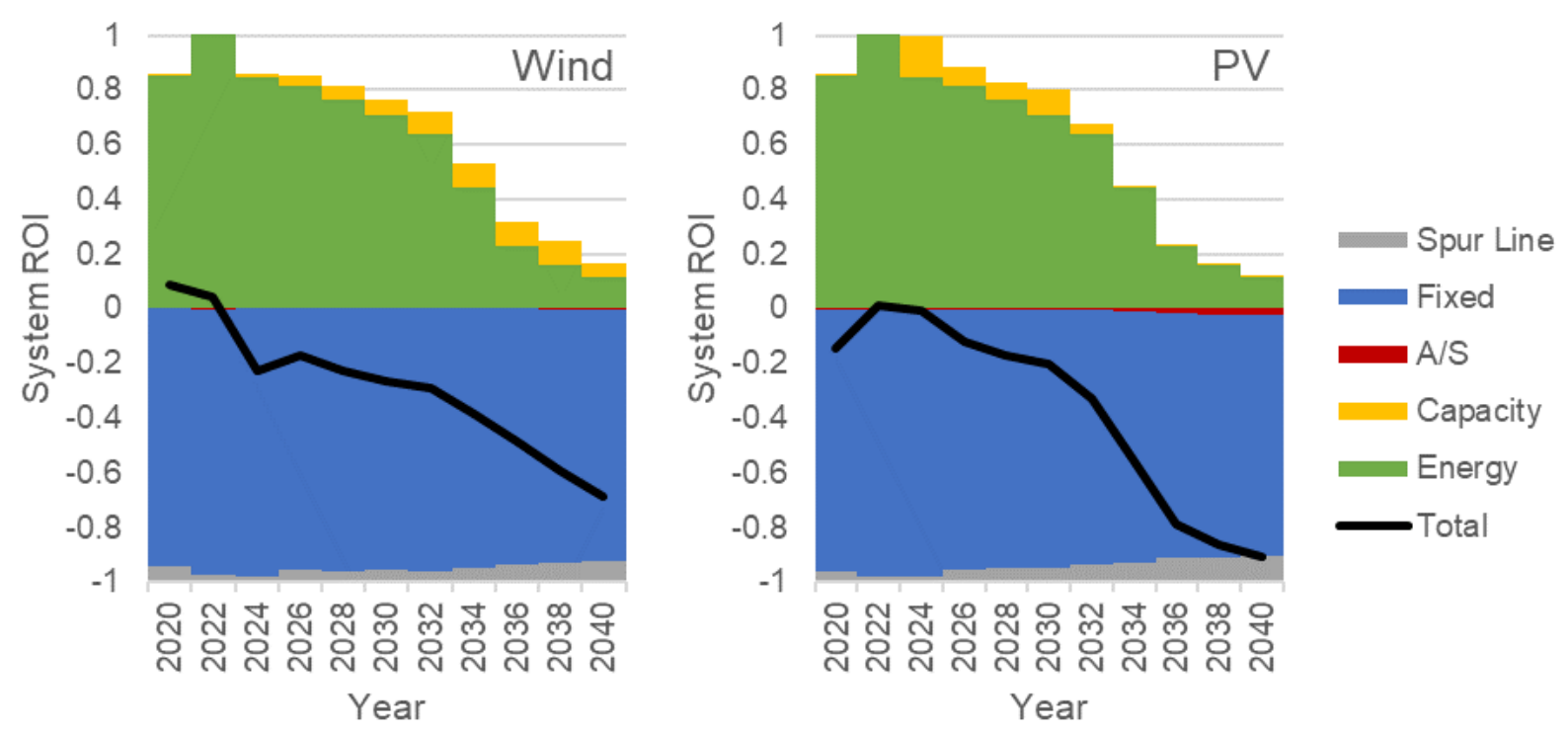

Figure 10. System ROI for onshore wind (left) and utility PV (right) over time with increasing penetration

The wind scenario reaches 51\% penetration by 2040 and the PV scenario reaches $41 \%$ penetration by 2040.

\footnotetext{
${ }^{62}$ Strictly speaking, ancillary services are reflected as negative values rather than costs because we assume increasing VRE leads to increasing operating reserve requirements.

${ }^{63}$ The increase in the capacity value component of system ROI for wind in Figure 10 is due to increasing capacity prices and the assumed increases in capacity factors for wind. More detailed analysis is needed to assess the validity of this assumption and these findings.
} 
The ReEDS modeling results presented in this section demonstrate how competitiveness metrics can be quantified using a CEM and illustrate some of the concepts with competitiveness metrics that we discussed in prior sections. The numerical values presented should not be considered definitive because many of them can be highly sensitive to modeling assumptions. These and other limitations associated with competitiveness metrics and their quantifications are described in Section 5.3.

\subsection{Limitations of Competitiveness Metrics and Their Quantifications}

Solutions from optimization models are only as good as the data, equations, and methods that comprise the formulations. Therefore, if competitiveness metrics are computed from model outputs, consumers of model results should be aware of the caveats of these models as well as the limitations of the metrics themselves.

First and foremost, each type of economic model represented can yield a different solution for a similar problem. Ruiz et al. (2014) compare different economic models (e.g., perfect competition, generalized Nash equilibrium) as applied to electricity market modeling. The optimal strategy of each firm in a market will depend on the ability of each firm to predict how its own behavior will impact market outcomes (i.e., price taker versus price maker). For example, the ReEDS model assumes perfect competition among all supply-side resources in the entire conterminous Unites States, but this may not accurately reflect the heterogeneity of market structures.

The amount of foresight assumed in a model can impact the timing of decisions. Myopic models may select technology options that are cost-optimal in the short run, but these assets may become stranded and no longer economic in future years as the model constraints and parameterizations evolve (e.g., a new policy is enacted; fuel prices fluctuate). Alternatively, models with perfect foresight select the long-run optimal strategies, but these models may be unrealistic from a practical planning perspective simply because future model parameters are highly uncertain. A sliding window approach (e.g., Cullenbine, Wood, and Newman 2011; Brown et al. 2001; Zheng et al. 2018) offers a compromise of moderate foresight. This foresight architecture permits a model to know the future with complete certainty within a short time window. The model makes decisions exclusively within this window and then progresses forward to a new window where new information is revealed about future conditions. For example, the ReEDS model is myopic with limited foresight (e.g., the model makes investment decisions one year at a time with anticipation of how natural gas fuel prices will change in the future). Therefore, the nearsighted decision making may only meet immediate system needs, with suboptimal reflections of long-term asset utilization.

The time resolution used for operational constraints within the model can affect the perceived value of each technology. Sufficient resolution is essential to capture the value of energy at the time it is delivered, especially with technologies like wind and solar, which have variable and uncertain output profiles. To capture these characteristics and other operational details, some models select representative subsets of chronological hours while other models select time blocks of non-chronological hours (see Sullivan, Eurek, and Margolis 2014). Coarse time scales and/or load duration curves are commonly used in CEMs to reduce the computational burden at the expense of solution accuracy; in one case, Nweke et al. (2012) examine the benefits of chronology over load duration curves, especially when considering the effects of wind and solar 
on the operation of the thermal fleet. For example, the ReEDS model uses 17 segments of nonchronological hours (i.e., time-slices) to capture the general diurnal profiles in four seasons. Although these time-slices inform average behavior of load, wind, and solar profiles, they do not capture the full distribution.

Other operational features that impact the estimated system value of technologies within models are flexibility and ancillary services. First, system flexibility is multifaceted and can be affected by a number of features, including thermal plant characteristics such as unit commitment, ramping requirements, and minimum operating levels; covariance of output profiles; the availability of storage; and demand-side services (e.g., demand response, interruptible load, load shifting). The degree of flexibility represented - and how well this flexibility is modeled — can impact the system value of VREs (Mills and Wiser 2014). Next, the types of ancillary services represented also affect the potential value of different technologies. For example, the ReEDS model does not capture non-spin replacement reserves, which would represent a value stream for rapid-starting plants, such as NG-CT and quick-start technologies. Furthermore, the absence of down reserves in ReEDS neglects possible value opportunities for wind turbines that could curtail to provide this product. Overall, higher resolution models are needed to directly represent these issues or to validate how well lower resolution models are representing the economic impacts of the flexibility and reserves.

Beyond the limitations of the models, important caveats exist for the metrics themselves. Calculating system value is difficult because prices, and therefore system value streams, are evolving over time, a result of changing levels of demand for electric sector services, changing cost and performance characteristics of the supply-side technologies, and uncertainty in the rate of retirement of technologies in the existing fleet. In addition, the system value is estimated based on marginal cost pricing; therefore, a finite investment in a technology itself will alter the prices of services it provides. Because of these reasons, metrics are useful for evaluating if technologies are economically viable or competitive, but do not give an indication of how much of a technology can be built economically without adjusting prices as we consider higher levels of deployment.

For the reasons outlined in this section, care is needed in interpreting any assessment of technology competitiveness and the metrics used. The modeling demonstration presented in this report is no exception and it is important to note that the numerical values presented are intended to be illustrative of the concepts of system value and competitiveness, which are our main focus. In particular, the ReEDS model used for our demonstration has numerous limitations particularly related to fidelity with respect to its representation of the grid services and technology capabilities. Future research is needed to improve these representations and expand the scenario analysis for a more-definitive and robust assessment of technology competitiveness. 


\section{Conclusions}

In this report, we introduce a new set of "system profitability metrics" to assess economic viability of electricity system technology options, compare relative competitiveness of options, and quantify the gap from viability for those options that are shown to be economically viable. We compare these system profitability metrics with other metrics from the power system economics literature that were developed in part to address the shortcomings of LCOE. Using a simple example, we demonstrate that although these existing metrics go beyond LCOE by considering system value, they do not robustly convey technology competitiveness from the direct standpoint of profitability.

In addition to reviewing and comparing the metrics, we discuss the sources of cost and value underlying them and describe how power sector planning models can be used to quantify costs, values, and metrics. We demonstrate one such capability using the ReEDS model, a capacity expansion model for the U.S. electricity system. Our demonstration uses illustrative scenarios to show cost and system value components as well as the range of competitiveness metrics for a set of generation technologies. We also show representations of the full onshore wind supply curveincluding sites that are economically viable and those that are not-from the standpoint of LCOE and that of the array of competitiveness metrics. Although all estimates in our demonstration are illustrative only, they offer a different perspective on how to view resources beyond that of traditional scenario modeling and sensitivity analysis. One potential application of competitiveness metrics is to assess the impacts of technology improvements, policy drivers, or other market factors on the economic viability of a resource (e.g., how many more gigawatts of resource would reach a certain threshold of economic viability after a specific action), without having to rely on potentially overly precise deployment scenario outcomes.

As any comprehensive competitiveness metric will necessarily consider an asset's system value as well as its costs, and system value can only be derived through interactions between the asset and the broader power system, a model, market prices, or some other means to reflect these interactions will be needed to quantify the metrics. This modeling requirement makes quantifying system value and competitiveness metrics significantly more difficult than simply calculating LCOE. This is especially true given that detailed model representations are needed to capture the multitude of grid requirements, temporal and spatial variations in the need for and price of grid services, and the interactions and competitions between options. Furthermore, models have several key limitations, including whether marginal prices from the model outcomes that are the basis of grid service value are robust when markets have finite depth. Whether a model has sufficient fidelity and resolution to capture the value of all grid services is another important consideration. Uncertainties associated with the future power system over the long lifetimes of many power system assets represent additional inherent limitations in developing competitiveness metrics from modeling. Depending on the use of the metrics, one should weigh these potential challenges with their added benefits. 


\section{References}

Blair, Nate, Nicholas DiOrio, Janine Freeman, Paul Gilman, Steven Janzou, Ty Neises, and Michael Wagner. 2018. System Advisor Model (SAM) General Description (Version 2017.9.5). NREL/TP-6A20-70414. Golden, CO: National Renewable Energy Laboratory. https://www.nrel.gov/docs/fy18osti/70414.pdf.

Bolinger, Mark, and Joachim Seel. 2018. Utility-Scale Solar: Empirical Trends in Project Technology, Cost, Performance, and PPA Pricing in the United States: 2018 Edition. Berkeley, CA: Lawrence Berkeley National Laboratory. https:/emp.lbl.gov/utility-scalesolar/?utm source=newsletter $110 \& u t m$ medium=email\&utm campaign $=$ Constant $\% 20$ Contact.

Brown, Gerald, Joseph Keegan, Brian Vigus, and Kevin Wood. 2001. "The Kellogg Company Optimizes Production, Inventory, and Distribution.” Interfaces 31 (6): 1-15.

Byers, Conleigh, Todd Levin, and Audun Botterud. 2018. "Capacity Market Design and Renewable Energy: Performance Incentives, Qualifying Capacity, and Demand Curves.” The Electricity Journal 31 (1): 65-74.

California Public Utilities Commission (CPUC). 2001. California Standard Practice Manual: Economic Analysis of Demand-Side Programs and Projects. http://www.cpuc.ca.gov/WorkArea/DownloadAsset.aspx?id=7741.

Cochran, Jacquelin, Paul Denholm, Bethany Speer, and Mackay Miller. 2015. Grid Integration and the Carrying Capacity of the US Grid to Incorporate Variable Renewable Energy.

NREL/TP-6A20-62607. Golden, CO: National Renewable Energy Laboratory. https://www.nrel.gov/docs/fy15osti/62607.pdf.

Cole, Wesley, Kelly Eurek, Nina Vincent, Trieu Mai, Matt Mowers, and Greg Brinkman. 2018. Operating Reserves in Long-Term Planning Models. NREL/PR-6A20-71148. Golden, CO: National Renewable Energy Laboratory. https:/www.nrel.gov/docs/fy18osti/71148.pdf.

Cole, Wesley, Will Frazier, Paul Donohoo-Vallett, Trieu Mai, and Paritosh Das. 2018. 2018 Standard Scenarios Report: A U.S. Electricity Sector Outlook. NREL/TP-6A20-71913. Golden, CO: National Renewable Energy Laboratory. https://www.nrel.gov/docs/fy19osti/71913.pdf.

Cullenbine, Christopher, R. Kevin Wood, and Alexandra Newman. 2011. "A Sliding Time Window Heuristic for Open Pit Mine Block Sequencing." Optimization Letters 5 (3): 365-77.

Dalla Riva, Alberto, János Hethey, and Aisma Vītina. 2017. Impacts of Wind Turbine Technology on the System Value of Wind in Europe. NREL/TP-6A20-70337. Golden, CO: National Renewable Energy Laboratory. https:/www.nrel.gov/docs/fy18osti/70337.pdf.

Dantzig, G.B. 1963. Linear Programming and Extensions. New Jersey: Princeton University Press.

Denholm, Paul, and Robert Margolis. 2007. "Evaluating the Limits of Solar Photovoltaics (PV) in Traditional Electric Power Systems.” Energy Policy 35: 2852-61. 
Denholm, Paul, Yinong Sun, and Trieu Mai. 2019. An Introduction to Grid Services: Concepts, Technical Requirements, and Provision from Wind. TP-6A20-72578. Golden, CO: National Renewable Energy Laboratory. https://www.nrel.gov/docs/fy19osti/72578.pdf.

Drury, Easan, Paul Denholm, and Robert Margolis. 2011. The Impact of Different Economic Performance Metrics on the Perceived Value of Solar Photovoltaics. NREL/TP-6A20-52197. Golden, CO: National Renewable Energy Laboratory. https://www.nrel.gov/docs/fy12osti/52197.pdf.

EIA (U.S. Energy Information Administration). 2018a. Annual Energy Outlook 2018. Washington, D.C.: EIA. https://www.eia.gov/outlooks/aeo/pdf/AEO2018.pdf.

- 2018b. Levelized Cost and Levelized Avoided Cost of New Generation Resources in the Annual Energy Outlook 2018. Washington, D.C.: EIA.

https://www.eia.gov/outlooks/aeo/pdf/electricity generation.pdf.

Ela, E., V. Gevorgian, P. Fleming, Y.C. Zhang, M. Singh, E. Muljadi, A. Scholbrook, et al. 2014. Active Power Controls From Wind Power: Bridging the Gaps. NREL/TP-5D00-60574. Golden, CO: National Renewable Energy Laboratory. https://www.nrel.gov/docs/fy14osti/60574.pdf.

Eurek, Kelly, Wesley Cole, David Bielen, Nate Blair, Stuart Cohen, Bethany Frew, Jonathan Ho, et al. 2016. Regional Energy Deployment System (ReEDS) Model Documentation: Version 2016. NREL/TP-6A20-67067. Golden, CO: National Renewable Energy Laboratory. https://www.nrel.gov/docs/fy17osti/67067.pdf.

Feldman, David, Galen Barbose, Robert Margolis, Ryan Wiser, Naïm Darghouth, and Alan Goodrich. 2012. Photovoltaic (PV) Pricing Trends: Historical, Recent, and Near-Term Projections. Golden, CO: National Renewable Energy Laboratory. https://www.nrel.gov/docs/fy13osti/56776.pdf.

FICO. 2018. Xpress-MP Optimization Suite. Minneapolis, MN: FICO.

Goldfarb, D., and J.K. Reid. “A Practicable Steepest-Edge Simplex Algorithm.” Mathematical Programming 12 (1): 361-71.

Gurobi. 2018. Gurobi Optimizer. Beaverton, OR: Gurobi. http://www.gurobi.com/.

Heuberger, Clara F., Iain Staffell, Nilay Shah, and Niall Mac Dowell. 2016. "Levelised Value of Electricity: A Systemic Approach to Technology Valuation." Computer Aided Chemical Engineering 38 (2016): 721-6.

https://www.sciencedirect.com/science/article/pii/B9780444634283501259.

- 2017. "A Systems Approach to Quantifying the Value of Power Generation and Energy Storage Technologies in Future Electricity Networks." Computers \& Chemical Engineering 107 (2017): 247-56. https://www.sciencedirect.com/science/article/pii/S0098135417302119. 
Hirth, Lion. 2013. "The market value of variable renewables: The effect of solar wind power variability on their relative price." Energy Economics 38 (2013): 218-236.

https://www.sciencedirect.com/science/article/pii/S0140988313000285.

Hirth, Lion, and Simon Müller. 2016. "System-Friendly Wind Power: How Advanced Wind Turbine Design Can Increase the Economic Value of Electricity Generated through Wind Power." Energy Economics 56 (2016): 51-63.

https://www.sciencedirect.com/science/article/pii/S0140988316300317.

Hirth, Lion, Falko Ueckerdt, and Ottmar Edenhofer. 2015. "Integration Costs Revisited: An Economic Framework for Wind and Solar Variability.” Renewable Energy 74 (2015): 925-39. https://www.sciencedirect.com/science/article/pii/S0960148114005357.

Hobbs, Benjamin F. 1995. "Optimization Methods for Electric Utility Resource Planning.” European Journal of Operational Research 83 (1): 1-20.

Hogan, Michael. 2017. "Follow the Missing Money: Ensuring Reliability at Least Cost to Consumers in the Transition to a Low-Carbon Power System." The Electricity Journal 30 (1): 55-61. https://www.sciencedirect.com/science/article/pii/S1040619016302512?via\%3Dihub.

Hummon, Marissa, Paul Denholm, Jennie Jorgenson, David Palchak, Brendan Kirby, and Ookie Ma. 2013. Fundamental Drivers of the Cost and Price of Operating Reserves. NREL/TP-6A2058491. Golden, CO: National Renewable Energy Laboratory. https://www.nrel.gov/docs/fy13osti/58491.pdf.

International Energy Agency (IEA). 2018. World Energy Outlook. https://www.iea.org/weo2018/.

IBM. 2018. ILOG CPLEX Optimization Studio. Incline Village, NV: IBM.

Jenkin, Thomas, David Feldman, Alan Kwan, and Brian Walker. 2019. Estimating the Impact of Residual Value for Electricity Generation Plants on Capital Recovery, Levelized Cost of Energy, and Cost to Consumers. NREL/TR-6A20-72217. Golden, CO: National Renewable Energy Laboratory.

Joskow, Paul L. 2011. "Comparing the Costs of Intermittent and Dispatchable Electricity Generating Technologies.” American Economic Review 101.3 (2011): 238-41. https://www.aeaweb.org/articles?id=10.1257/aer.101.3.238.

Lamont, Alan D. 2008. "Assessing the Long-Term System Value of Intermittent Electric Generation Technologies.” Energy Economics 30 (3): 1208-31.

Lazard. 2017. Lazard's Levelized Cost of Energy Analysis: Version 11.0. Hamilton, Bermuda: Lazard. https://www.lazard.com/media/450337/lazard-levelized-cost-of-energy-version-110.pdf.

Mills, Andrew D., and Ryan H. Wiser. 2012. "Changes in the Economic Value of Photovoltaic Generation at High Penetration Levels: A Pilot Case Study of California." In 2012 IEEE 38th Photovoltaic Specialists Conference (PVSC) Part 2. IEEE. https://ieeexplore.ieee.org/abstract/document/6656763/. 
- 2013. An Evaluation of Solar Valuation Methods Used in Utility Planning and Procurement Processes. Berkeley, CA: Lawrence Berkeley National Laboratory. https://www.osti.gov/biblio/1171527.

. 2014. Strategies for Mitigating the Reduction in Economic Value of Variable Generation with Increasing Penetration Levels. LBNL-6590E. Berkeley, CA: Lawrence Berkeley National Laboratory. https://emp.lbl.gov/sites/all/files/lbnl-6590e.pdf.

Mills, Andrew D., Dev Millstein, Seongeun Jeong, Luke Lavin, Ryan H. Wiser, and Mark Bolinger. 2018. "Estimating the Value of Offshore Wind Along the United States' Eastern Coast." Environmental Research Letters 13 (9). https://emp.lbl.gov/publications/estimatingvalue-offshore-wind-along.

Monitoring Analytics. 2018. PJM Market Monitor Report: Section 7: Net Revenue. http://www.monitoringanalytics.com/reports/PJM State of the Market/2017/2017-som-pimsec7.pdf.

Müller, Simon, Hannele Holtinen, Emanuele Taibi, J. Charles Smith, Daniel Fraile, and Til Kristian Vrana. 2018. "System Integration Costs: A Useful Concept that is Complicated to Quantify?" $17^{\text {th }}$ Wind Integration Workshop. Stockholm, Sweden.

NERC. 2018. Glossary of Terms Used in NERC Reliability Standards. https://www.nerc.com/pa/Stand/Glossary\%20of\%20Terms/Glossary_of_Terms.pdf

NREL (National Renewable Energy Laboratory). 2018. "NREL Annual Technology Baseline (ATB)." https://atb.nrel.gov/.

Nweke, Charles I., Frank Leanez, Glenn R. Drayton, and Mohan Kolhe. 2012. "Benefits of Chronological Optimization in Capacity Planning for Electricity Markets." In Power System Technology (POWERCON), 2012 IEEE International Conference, pp. 1-6.

Reichenberg, Lina, Fredrik Hedenus, Mikael Odenberger, and Filip Johnsson. 2018. "The Marginal System LCOE of Variable Renewables-Evaluating High Penetration Levels of Wind and Solar in Europe." Energy 152 (2018): 914-24.

https://www.sciencedirect.com/science/article/pii/S0360544218302895.

Ruiz, Carlos, Antonio J. Conejo, J. David Fuller, Steven A. Gabriel, and Benjamin F. Hobbs. 2014. "A Tutorial Review of Complementarity Models for Decision-Making in Energy Markets." EURO Journal on Decision Processes 2 (1-2): 91-120.

Short, Walter, Daniel J. Packey, and Thomas Holt. 1995. A Manual for the Economic Evaluation of Energy Efficiency and Renewable Energy Technologies. NREL/TP-462-5173. Golden, CO: National Renewable Energy Laboratory. https://www.nrel.gov/docs/legosti/old/5173.pdf.

Siler-Evans, Kyle, Ines Lima Azevedo, M. Granger Morgan, and Jay Apt. 2013. "Regional Variations in the Health, Environmental, and Climate Benefits of Wind and Solar Generation." PNAS 110 (29): 11768-73. http://www.pnas.org/content/pnas/110/29/11768.full.pdf. 
Sullivan, Patrick, Kelly Eurek, and Robert Margolis. 2014. Advanced Methods for Incorporating Solar Energy Technologies Into Electric Sector Capacity-Expansion Models: Literature Review and Analysis. NREL/TP-6A20-61185. Golden, CO: National Renewable Energy Laboratory. https://www.nrel.gov/docs/fy14osti/61185.pdf.

Ueckerdt, Falko, Lion Hirth, Gunnar Luderer, and Ottmar Edenhofer. 2013. "System LCOE: What are the Costs of Variable Renewables?" Energy 63 (2013): 61-75. https://www.sciencedirect.com/science/article/pii/S0360544213009390.

Wilkerson, Jordan, Peter Larsen, and Galen Barbose. 2014. "Survey of Western U.S. Electric Utility Resource Plans.” Energy Policy 66 (2014): 90-103.

Wiser, Ryan H., A.D. Mills, J. Seel, T. Levin, and A. Botterud. 2017. Impacts of Variable Renewable Energy on Bulk Power System Assets, Pricing, and Costs. Berkeley, CA: Lawrence Berkeley National Laboratory.

https://emp.lbl.gov/sites/default/files/lbnl_anl_impacts_of_variable_renewable_energy_final.pdf.

Zheng, Yingying, Bryan M. Jenkins, Kurt Kornbluth, and Chresten Træholt. 2018. "Optimization Under Uncertainty of a Biomass-Integrated Renewable Energy Microgrid With Energy Storage." Renewable Energy 123 (2018): 204-17.

Zhou, Zhi, Todd Levin, and Guenter Conzelmann. 2016. Survey of U.S. Ancillary Services Markets. ANL/ESD-16/1. Argonne, IL: Argonne National Laboratory.

https://www.osti.gov/biblio/1236451. 


\section{Appendix A: Metrics Equations}

This appendix presents the mathematical equations and units for the metrics and key terms used by the metrics. Since many electric system assets are long-lived with a combination of fixed and operating costs, most expressions reflect the present value of a quantity. To facilitate this, we define $v_{t}$ as the present value discount factor, where $t$ is the number of years from the assumed present:

$$
v_{t}:=\frac{1}{(1+d)^{t}}
$$

For simplicity, we assume the discount factor compounds annually, although the same analysis can be done with any compounding period. Also for simplicity, we assume constant and uniform annual discount rate $d$, and evaluation period $Y$ for all technologies. More complex treatment for present value calculations, such as technology- and year-specific discount rates and evaluation periods, may be appropriate but are outside the scope of our analysis. However, even as these complexities could impact the quantitative estimates for the metrics, they do not affect our conceptual discussion of the metrics themselves.

We also define $C R F$ as the "capital recovery factor", used to calculate the annuity associated with evaluation period $Y$ and discount rate $d$ :

$$
C R F:=\frac{d *(1+d)^{Y}}{(1+d)^{Y}-1}
$$

System value of a technology is derived from the provisions of electricity sector services by that technology and the marginal costs of those services, and both technology provisions and marginal costs can vary from year to year, temporally within each year, and from one location to the next. We define $P_{x, h, t}^{S}$ as the marginal cost (real dollars per service unit) for service $S$ in location $x$ during time period $h$ in year $t$, and $Q_{x, h, t}^{S, T}$ as the quantity (provision) of service units from technology $T$ for the same service, location, time period, and year. Based on these quantities and prices, we define $V_{x, t}^{T}$ as the annual system value of a technology $T$ at location $x$ in year $t$ :

$$
V_{x, t}^{T}:=\sum_{S, h} Q_{x, h, t}^{S, T} P_{x, h, t}^{S}
$$

The units of $V_{x, t}^{T}$ are real, undiscounted dollars. We use the discount factor above, $v_{t}$, to define system value $V_{x}^{T}$ of technology $T$ at location $x$ in present value dollar terms:

$$
V_{x}^{T}:=\sum_{t=0}^{t=Y} V_{x, t}^{T} v_{t}
$$

where $Y$ is the evaluation period. Similarly, we define $C_{x, t}^{T}$ as the as the total costs of technology $T$ at location $x$ in year $t$, including capital, operation and maintenance, fuel, and any other costs, 
and $C_{x}^{T}$ as the present value of all costs incurred over the evaluation period for the same technology and location:

$$
C_{x}^{T}:=\sum_{t=0}^{t=Y} C_{x, t}^{T} v_{t}
$$

Similarly, we define $E_{x, t}^{T}$ as the as the electrical energy produced by technology $T$ at location $x$ in year $t$, and $E_{x}^{T}$ as the present value of all electrical energy produced over the evaluation period for the same technology and location:

$$
E_{x}^{T}:=\sum_{t=0}^{t=Y} E_{x, t}^{T} v_{t}
$$

We define $L C O E_{x}^{T}$ as the levelized cost of electricity of technology $T$ at location $x$, and $L V O E_{x}^{T}$ as the levelized cost of electricity of the same technology and location:

$$
\begin{aligned}
& \operatorname{LCOE}_{x}^{T}:=C_{x}^{T} / E_{x}^{T} \\
& \operatorname{LVOE}_{x}^{T}:=V_{x}^{T} / E_{x}^{T}
\end{aligned}
$$

We define $F_{x}^{T}$ as value factor of technology $T$ at location $x$ :

$$
F_{x}^{T}:=L V O E_{x}^{T} / \bar{P}
$$

Where $\bar{P}$ is a "benchmark price" of the system. Next we define the normalized "net value" metrics of technology $T$ at location $x . N V O C_{x}^{T}$ is the net value of capacity, $N V O E_{x}^{T}$ is the net value of electricity, and $S L C O E_{x}^{T}$ is the system LCOE:

$$
\begin{gathered}
N V O C_{x}^{T}:=\operatorname{CRF} *\left(V_{x}^{T}-C_{x}^{T}\right) / I_{x}^{T} \\
N V O E_{x}^{T}:=\left(V_{x}^{T}-C_{x}^{T}\right) / E_{x}^{T} \\
S L C O E_{x}^{T}:=\left(C_{x}^{T}-V_{x}^{T}\right) / E_{x}^{T}+\bar{P}
\end{gathered}
$$

Where $I_{x}^{T}$ is the installed capacity of technology $T$ at location $x$, and $C R F$ is used to annualize the present value of costs and values of $N V O C_{x}^{T}$ to convert to units of $\$ / k W / y r$.

Finally, we introduce the system profitability metrics of technology $T$ at location $x . B C R_{x}^{T}$ is the system benefit-cost ratio, $R O I_{x}^{T}$ is the system return on investment, $P M_{x}^{T}$ is the system profit margin, and $P L C O E_{x}^{T}$ is the profitability-adjusted LCOE:

$$
\begin{gathered}
B C R_{x}^{T}:=V_{x}^{T} / C_{x}^{T} \\
R O I_{x}^{T}:=\left(V_{x}^{T}-C_{x}^{T}\right) / C_{x}^{T}=B C R_{x}^{T}-1 \\
P M_{x}^{T}:=\left(V_{x}^{T}-C_{x}^{T}\right) / V_{x}^{T}=1-B C R_{x}^{T} \\
P L C O E_{x}^{T}:=\bar{P} *\left(C_{x}^{T} / V_{x}^{T}\right)=L C O E_{x}^{T} / F_{x}^{T}
\end{gathered}
$$




\section{Appendix B: Application of System Profitability to Linear Program Solution Methods}

Economic models, including CEMs of electricity systems, are often represented as mathematical programing problems and are solved using specialized software such as CPLEX (IBM 2018), Gurobi (Gurobi 2018), and XPRESS-MP (FICO 2018). The solver chooses values for a set of decision variables (e.g., how much of a technology to build in a specific location) that optimize an objective function (e.g., minimize cost or maximize profit) subject to a set of constraints (e.g., the supply of electricity must equal demand). Together, the decision variables, objective function, and constraints make up the problem formulation. Many CEMs of the electricity sector are formulated as LPs - a set of linear constraints and continuous decision variables. ${ }^{64}$ An LP is a model of perfect competition, and the solution to the LP is characterized by a competitive equilibrium. Competitive markets assume - among other things - product homogeneity, perfect information, and free cost to entry.

\section{B.1 LP Simplex Method}

Several computational algorithms have been developed to solve LPs. The most well-known of these methods is the simplex method (Dantzig 1963), an iterative algorithm that systematically evaluates feasible solutions one by one until optimality is reached. We summarize this algorithm into words using a generalized LP model of an electricity system as an example. In this LP, the objective is to minimize the cost of meeting electricity sector requirements from a group of technologies with various costs and ability to meet those requirements.

1. First, select an initial set of candidate technologies to participate in the market (i.e., "the participants") with associated costs and contributions to electricity sector requirements. The remaining set of technologies have not entered the market and are not contributing to requirements.

2. Solve the system of equations that govern the operation of the participants. At this point, the focus is computing a feasible solution and cost is irrelevant.

3. Given a feasible solution to the system of equations, calculate the marginal prices (also called dual prices or shadow prices) for each electricity sector requirement (i.e., constraint). A marginal price is the clearing price for a competitive market and represents the cost of the most expensive participant that was used to satisfy the constraint.

4. Next, calculate if any of the technologies that are not currently participating in the market would make positive profit (total system value from providing electricity sector requirements minus total cost) by entering the market. If none of the non-participating technologies can make positive profits, we know that the candidate set of market participants is optimal. However, if at least one of the non-participating technologies can make profit by entering the market, there exists a non-optimal solution and the candidate set must be revised.

\footnotetext{
${ }^{64}$ Another common formulation of electricity sector CEMs is as a mixed integer linear program (MILP) — a set of linear equations with continuous and/or discrete decision variables (IBM 2018; Gurobi 2018; FICO 2018), where continuous decision variables exist in the real number domain (e.g., the output of a wind plant), while discrete decision variables exist in the integer domain (e.g., the number of wind plants installed).
} 
5. If it is determined (from step 3) that a non-participating technology should enter the market (i.e., a "new entrant"), it then follows that one of the incumbent participants must exit the market - in essence, a swap is made. To determine the new entrant, one of a set of "pivot rules" is used. Once chosen, the new entrant will take the market share from one of the incumbent technologies, the "exiting" technology. After the swap, there exists a new set of participants that can be evaluated starting again at step 1.

The above algorithm continues until an optimal solution is found during step 3. At optimality, we have a solution such that modeled system values are enough to cover the modeled cost, both for the entire system and for each technology individually. ${ }^{65}$ This solution to this LP-the level of output for generators, costs, and marginal prices - can be used to compute the various output metrics discussed in this report.

\section{B.2 System Profitability as a Pivot Rule in the Simplex Method}

The selection of a new entrant via a pivot rule (see step 4 above) has significant impact on the execution time of the simplex algorithm through two avenues. The first is by affecting the number of iterations - a good pivot rule would select new entrants that have a high chance of being in the optimal solution, reducing unnecessary iterations. The second impact is on the execution time of each iteration due to the computational requirements of the pivot rule itself. There is often a tradeoff between these two factors. For example, certain pivot rules perform more complex logic in the selection of a new entrant, which may reduce iterations, but the additional computational complexity increases the execution time of each iteration.

The first pivoting rule ever developed, "Dantzig's rule" (Dantzig 1963), picks the new entrant as the variable with the maximum profit per unit of a variable. This method takes advantage of the fact that the negative profit per unit variable, called "reduced cost," is a readily available value for every variable, so the computational cost for each iteration is very low. However, as with the "net value" metrics discussed in this report (e.g. NVOE and NVOC), reduced cost is not directly comparable between variables because the economic value of a unit variable to the system varies. To make this clearer, for an electric sector model with variables for installed capacity of each technology, Dantzig's method would select the technology with the highest NVOC as the new entrant, and in this report we have shown that NVOC is a distorted measure of relative competitiveness.

We introduce new pivot rules based on system profitability. Rather than sorting variables, $i$,by reduced cost, $\bar{c}_{l}$, we sort by system ROI, $R O I_{i}$, or system profit margin, $P M_{i}$. Here are the calculations of $R O I_{i}$ and $P M_{i}$, where $c_{i}$ is the cost per unit of variable (i.e., objective coefficient):

$$
\begin{gathered}
R O I_{i}=-\frac{\overline{c_{i}}}{\bar{c}_{i}} \\
P M_{i}=\frac{\overline{c_{i}}}{\overline{c_{i}}-c_{i}}
\end{gathered}
$$

\footnotetext{
${ }^{65}$ Using the terminology of this report, this means NVOE, NVOC, and system ROI are equal to 0 for all technologies that are chosen in the solution, while the technology options that are not chosen have NVOE, NVOC, and system ROI values that are less than 0 .
} 
Depending on whether it makes more sense to use system ROI or system profit margin as the metric of comparison, the variable with the highest $R O I_{i}$ or $P M_{i}$, respectively, would be chosen as the variable to swap into the solution. Note that certain variables may not appear in the objective function, meaning $c_{i}=0$, and $R O I_{i}$ is undefined. For this reason, system profit margin may be preferable to system ROI as the metric of comparison.

Other pivot rules have been investigated that attempt to improve on Dantzig's method in similar ways. For example, the Steepest Edge Rule (Goldfarb and Reid 1977) similarly normalizes reduced cost, but instead of normalizing by objective coefficient, it normalizes by distance along the edge of a traversal in the variable space of the problem. However, this is computationally more expensive than either of the proposed system profitability pivot rules. Future research is needed to test the computational advantages and disadvantages of the system profitability-based pivot rules introduced here. 